\title{
Integration of prophages into CRISPR loci remodels viral immunity in Streptococcus pyogenes.
}

Andrew Varble ${ }^{1}$, Edmondo Campisi ${ }^{2}$, Chad W. Euler ${ }^{2,3}$, Jessica Fyodorova ${ }^{1}$, Jakob T RostøI ${ }^{1}$, Vincent A. Fischetti ${ }^{2}$, and Luciano A. Marraffini ${ }^{1,4}$

${ }^{1}$ Laboratory of Bacteriology, The Rockefeller University, New York, NY, USA.

'Laboratory of Bacterial Pathogenesis and Immunology, The Rockefeller University, New York, NY, USA.

${ }^{3}$ Department of Medical Laboratory Sciences, Hunter College, CUNY, New York, NY, USA.

${ }^{4}$ Howard Hughes Medical Institute, The Rockefeller University, New York, NY, USA. 


\section{Summary}

CRISPR loci are composed of short DNA repeats separated by sequences that match the genomes of phages and plasmids, known as spacers. Spacers are transcribed and processed to generate RNA guides used by CRISPR-associated nucleases to recognize and destroy the complementary nucleic acids of invaders. To counteract this defense, phages can produce small proteins that inhibit these nucleases. Here we demonstrate that the ФAP1.1 temperate phage utilizes an alternate approach to antagonize the type II-A CRISPR response in Streptococcus pyogenes. Immediately after infection this phage expresses a canonical anti-CRISPR, AcrllA23 that prevents Cas9 function, allowing ФAP1.1 to integrate into the direct repeats of the CRISPR locus and neutralizing immunity. However, acrllA23 is not transcribed during lysogeny and phage integration/excision cycles can result in the deletion and/or transfer of spacers, enabling a complex modulation of the type II-A CRISPR immune response. 


\section{Introduction}

Clustered, regularly interspaced, short, palindromic repeat (CRISPR) loci provide prokaryotic organisms with adaptive immunity against invading nucleic acids, including viruses (Barrangou et al., 2007) and plasmids (Marraffini and Sontheimer, 2008). CRISPR loci are composed of short direct repeats (DRs) separated by equally short sequences that match the genomes of the invader, known as spacers. Usually, the terminal repeat (DRt) is not identical to the rest of the DRs, and marks the end of the CRISPR array (Jansen et al., 2002). In the first phase of CRISPR immunity, new spacer sequences are acquired from the infecting DNA, and integrated between two repeats in the CRISPR array (Barrangou et al., 2007). In the second phase, spacers are transcribed and processed to generate RNA guides used by CRISPR-associated (Cas) nucleases to recognize and destroy the complementary nucleic acids of invaders (Brouns et al., 2008; Garneau et al., 2010; Marraffini and Sontheimer, 2008). Depending on the content of CRISPR-associated (cas) genes, CRISPR loci are classified into six different types and multiple subtypes (Makarova et al., 2020). The type II-A CRISPRCas system of Streptococcus pyogenes has been extensively studied, not only for its role in phage defense (Heler et al., 2015; Modell et al., 2017), but also for the biotechnological applications of its signature RNA-guided nuclease, Cas9 (Cong et al., 2013; Jinek et al., 2012; Mali et al., 2013). During phage infection a small number of cells acquire a 30-nucleotide spacer sequence from the viral genome, which is integrated between the 36-nucleotide DRs (McGinn and Marraffini, 2016; Wright and Doudna, 2016; Xiao et al., 2017). DRs and spacers are transcribed into a single preCRISPR-RNA (pre-crRNA), which is subsequently processed into mature crRNA guides 
after interaction of the DR and 5' end of the trans-activating crRNA (tracrRNA), a small RNA cofactor of Cas9 (Deltcheva et al., 2011). The dsRNA formed through this interaction is cleaved by RNase III (Deltcheva et al., 2011), to create the mature crRNA and activate the Cas9 nuclease complex, which can use the spacer sequence to find complimentary targets in invading DNA (Jinek et al., 2012).

S. pyogenes (also known as the group A streptococcus), an important human pathogen, is the causative agent of a variety of diseases such as scarlet fever, pharyngitis, impetigo, cellulitis, necrotizing fasciitis and toxic shock syndrome (2016). A significant number of the virulence genes responsible for $S$. pyogenes pathogenicity are harbored within prophages integrated throughout the chromosome (Fischetti, 2007). Integration typically occurs after the injection and circularization of the of the viral genome, during the lysogenic cycle of temperate phages (Howard-Varona et al., 2017). It usually requires recombination between specific sequences in the phage $(a t t P)$ and the bacterial (attB) DNA, which generates two new sites at the left (attL) and right (attR) borders of the inserted prophage. Changes in the environment causing bacterial stress can induce the lytic cycle of the prophage, resulting in the excision and replication of the viral genome, followed by the formation and release of new viral particles that can infect other hosts (Howard-Varona et al., 2017). In S. pyogenes this process contributes to the spread of the virulence genes carried by the temperate phages (Fischetti, 2007). In addition, inaccurate prophage excision and/or DNA packaging during induction can lead to the transduction of bacterial sequences into new hosts (McCullor et al., 2018). Recently, a comprehensive study of 118 complete S. pyogenes genome sequences determined that they collectively harbor 373 prophages (Yamada et al., 2019). In 
addition to the type II-A CRISPR system described above, which is present in 21 genomes, 20 S. pyogenes strains contained type I-C CRISPR loci, and 39 strains displayed both systems. However, genomes hosting a lower number of prophages had on average a significantly higher number of type II-A rather than type I-C spacers, suggesting that type I-C CRISPR systems are less efficient at preventing prophage spread, perhaps even non-functional (Yamada et al., 2019). The analyzed type II-A CRISPR arrays contained a total of 139 unique spacer sequences, of which 126 matched diverse S. pyogenes prophages and phages. Given the importance of prophage acquisition for $S$. pyogenes pathogenesis, the targeting of these mobile elements by type II-A CRISPR-Cas systems is expected to have profound consequences for the virulence of this organism.

Invaders must develop strategies to combat their host's defenses. Type II-A CRISPRCas immunity is most commonly evaded by phages containing target mutations that prevent recognition and cleavage by Cas9 (Deveau et al., 2008; Gasiunas et al., 2012; Jinek et al., 2012). In addition, some phages also produce anti-CRISPR (Acr) proteins that specifically inhibit Cas nucleases (Davidson et al., 2020). Although none have been isolated from S. pyogenes phages, multiple Acrs that prevent the function of different type II-A Cas9 nucleases with diverse mechanisms of inhibition have been reported (Eitzinger et al., 2020; Forsberg et al., 2019; Hynes et al., 2017; Mahendra et al., 2020; Rauch et al., 2017; Uribe et al., 2019). Acrs are typically present in temperate phages and are robustly transcribed in both the lytic and latent cycles immediately after infection (Bondy-Denomy et al., 2013; Stanley et al., 2019). However, this elevated expression is not sufficient to inhibit all the crRNA-guided Cas nucleases present in the host cell and 
multiple rounds of infection (and Acr delivery) are required to neutralize the CRISPR immune response (Borges et al., 2018; Landsberger et al., 2018). Importantly, the initial high levels of transcription of the acr operon are detrimental to the propagation of the phage, as it interferes with the proper transcription of other viral genes required for the later stages of the infection cycle. This is prevented by the aca repressor, which is usually located next to the acr genes, and contains a helix-turn-helix DNA-binding domain to regulate the transcription of the operon (Stanley et al., 2019). Aca repression, however, is not complete since prophages can produce basal amounts of Acr that can inhibit CRISPR immunity in the lysogen.

In addition to the expression of virulence factors and anti-CRISPRs, temperate phages can modulate host phenotypes by integrating and disrupting genes that carry attB sites (Coleman et al., 1991; Lee and Iandolo, 1986; Taylor, 1963). A bioinformatic study reported two closely related S. pyogenes strains (SSI-1 and MGAS315) harboring prophages inserted into the repeats of the CRISPR array (Nozawa et al., 2011), an observation that suggests a new mechanism used by phages to inhibit CRISPR. Here we studied a member of this temperate phage family, ФAP1.1, to determine whether and how type II-A CRISPR-Cas immunity is affected by prophage integration into the CRISPR repeats. We found that immediately after infection this phage expresses a canonical anti-CRISPR, AcrllA23 that inhibits Cas9. However, acrllA23 is not transcribed from the prophage genome during lysogeny. Instead, the genesis of mature crRNA guides, and thus the ability of Cas 9 to recognize the phage, is prevented by the integration of ФAP1.1 into the direct repeats of the CRISPR locus. In addition, phage integration/excision cycles can result not only in the deletion of spacers, but also in the 
transduction of spacer-repeat units carried within the viral genomes. Our results reveal a new phage strategy that both modulates the type II-A CRISPR immune response and drives evolution on both sides of the host/pathogen conflict.

\section{Results}

The temperate phage ФAP1.1 integrates into the repeat sequences of the S. pyogenes type II-A CRISPR array

We performed a bioinformatic search within all available $S$. pyogenes genomes to identify prophages integrated into the different CRISPR arrays carried by this organism. In agreement with previous analysis (Nozawa et al., 2011; Yamada et al., 2019), we found that while none of the type I-C loci contained prophages, twelve different strains harbored almost identical prophages inserted into the type II-A CRISPR array (Fig. S1A). In most cases only a single degenerate terminal repeat (DRt) was present and was interrupted by the viral genome, with the exception of strains 1085 and MGAS10786, where the prophage integrated into the first repeat and was followed by an intact CRISPR array.

To understand if and how temperate phages integrate into the type II-A CRISPR locus, we isolated the phage ФAP1.1 from strain AP1 (Fiebig et al., 2015) (Fig. S1B). Sequencing of the isolated phage revealed that it is a cos phage harboring an attP site with 8 base-pairs identical to the DR and DRt, the attB for this phage (Fig. 1A). To facilitate the isolation and quantification of lysogens, we added a spectinomycin resistance cassette to ФAP1.1 (Fig. S1B). This phage was then used to infect $S$. 
pyogenes K56 (Kjems, 1958), a strain containing a CRISPR array of 2 spacers, 2 DRs, and one DRt (Fig. 1B). In principle, integration could occur in each of the three attB sites contained within the repeats (DR1, DR2 and DRt), therefore we extracted genomic DNA from bacteria collected 24 hours after infection and performed PCR with primers that specifically amplify the attL and attR. We obtained three PCR products separated by approximately 66 base-pairs, indicative of phage integration into all the repeats, with a preference for DR1, DR2 and then DRt, according to the intensity of the DNA band (Fig. 1C). To confirm and quantify the integration events, we isolated 100 individual lysogens and sequenced the att $L$ and att $R$. We found that indeed, ФAP1.1 integrated into every direct repeat, but with a marked preference for DR1, where a majority of the attL and attR (Fig. 1D) sites were positioned. Due to this, prophage integration typically conserved the original repeat-spacer content, with 75/100 lysogens maintaining the two original spacers (Fig. 1E) where the attL and attR are inserted into the same repeat (Fig. 1F). Finally, a fraction of the insertion events led to CRISPR rearrangements that resulted in either the deletion of one or both spacers (23/100, Fig. 1E) where the attL and attR were located across different repeats (Fig. 1F), or in spacer duplication events, (2/100, Figs. 1E, S1C). These data demonstrate that although ФAP1.1-like phages are typically detected within a single DRt, they are able to integrate into any repeat of a canonical CRISPR array.

\section{ФAP1.1 integration disrupts spacer transcription and crRNA processing}

To determine if lysogenization could be possible in the presence of a spacer that targets the infecting phage, we investigated lysogenization in $S$. pyogenes CEM1 $\Delta \Phi$ (Euler et 
al., 2016), an SF370 (Desiere et al., 2001) derivative lacking all prophages (Fig. 2A). In CEM1 $\Delta \Phi$, one of its six spacers (spc4) has a partial match to ФAP1.1 (Fig. S1B, D). We transformed this strain and a mutant lacking spacers 2-5 (CEM1 $\Delta \Phi[\Delta 2-5])$ with a plasmid harboring the phage target (pTgt4) and confirmed that this sequence is targeted by the type II-A CRISPR-Cas system (Fig. 2B). We then infected strain CEM1 $\Delta \Phi$ with ФAP1.1 and analyzed the location of attL and attR by sequencing the PCR products of 100 lysogens. Interestingly, integration of the attL was only observed in the first five DRs, but not in DR6 nor DRt, of the CRISPR array of strain CEM1 $\Phi$ (Fig. 2C). Other parameters were similar to those obtained for strain K56: attRs were detected in every DR (Fig. 2C) and most integration events maintained the original composition of the CRISPR array, with a low frequency of spacer deletions (Figs. 2D, E). The presence of spc4 in most lysogens suggested that the immunity mediated by this spacer was neutralized by the insertion of ФAP1.1 into the CRISPR array. Indeed, targeting of the pTgt4 plasmid was abolished in lysogens that had the prophage integrated into DRs one through five (maintaining the entire spacer repertoire), as well as a lysogen where all spacers were eliminated due to integration into both DR1 and DRt (DR1-t, Fig. 2F).

We also measured type II-A immunity mediated by spc1 and spc5 through transformation of additional plasmids harboring targets for each of these spacers (Fig. 2F). Immunity by spc1 was abolished by the presence of prophages integrated into DR1 and DR2; i.e., immediately upstream and downstream of the targeting spacer. For spc5, all prophages were integrated in upstream DRs and eliminated efficient targeting. Taken together these data suggest that all spacers downstream of the prophage integration site lose their ability to provide immunity, most likely due to interruption of the 
transcription of the CRISPR array. Also, the spacer immediately upstream of the prophage integration site is ineffective, presumably due to the elimination of repeat sequences that are needed in the pre-crRNA to interact with the tracrRNA during crRNA processing (Deltcheva et al., 2011). To explore this hypothesis, we performed Northern blots to detect spc4, spc1 and spc5 crRNAs in the different lysogens and found that all lysogens that lacked type II-A immunity in the transformation assay of Figure 2F did not produce the targeting mature crRNA (Fig. 2G). Therefore, we conclude that the integration of ФAP1.1 in DR1 through DR5 occurs because it prevents the generation of spc4 crRNA and thus Cas9 cleavage of the residing prophage. Furthermore, we corroborated this pattern of integration by infecting S. pyogenes strain NCTC13743 (accession number NZ_LS483384), in which the type II-A CRISPR array contains three spacers that target ФAP1.1: spc2, spc6 and spc9 (Figs. S1B, S2A, S2B). We first verified that the type II-A CRISPR system present in this strain is capable of restricting a plasmid containing the three target sequences present in ФAP1.1 (Fig. S2C). We then infected this triple-targeting strain with ФAP1.1 and analyzed the prophage location in 25 different lysogenic colonies. We found that a majority of phage integrated into DR2 or DR3; i.e., immediately upstream or downstream of spc2, thus neutralizing the immunity provided by this spacer as well as that of the two other downstream targeting spacers (Fig. S2D). Integration events also occurred in repeat sequences downstream of DR3, however they were accompanied by deletions encompassing the upstream targeting spacers. Altogether these data demonstrate that lysogenization of ФAP1.1 into the repeats of a CRISPR array that harbors targeting spacers neutralizes these 
spacers, either by preventing the generation of the targeting crRNA or though deletion of the targeting spacer.

ФAP1.1 harbors an inhibitor of the S. pyogenes type II-A CRISPR-Cas system

Although lysogenization can eventually block targeting after prophage integration, the phage should still be vulnerable to Cas9 recognition and cleavage during DNA injection, (Modell et al., 2017) and even shortly after phage integration, as molecules of Cas9 loaded with spc4 crRNA will be present in the host cell for a period of time. It is possible a small number of infecting phage stochastically avoid Cas9 cleavage before integration. If this is the case, it will be expected that hosts targeting ФAP1.1 will display a decrease in the frequency of lysogenization compared to hosts that cannot restrict the phage. To test this, we enumerated lysogens after infection of CEM1 $\triangle \Phi$ and CEM1 $\Delta \Phi[\Delta 2-5]$ streptococci (Fig. 3A). Surprisingly, we found a minimal effect of type IIA immunity on ФAP1.1 lysogenization. The same outcome was observed when the triple-targeting S. pyogenes strain NTCT13743 and its non-targeting mutant derivative NTCT13743[ $\Delta 2-10]$ were infected with ФAP1.1 (Fig. S3A). Therefore, both results suggested the presence of a mechanism that avoids Cas9 targeting pre-integration.

ФAP1.1 contains a four-gene locus with a similar arrangement to previously identified anti-CRISPR (acr) loci (Pawluk et al., 2016; Stanley et al., 2019); i.e., it occurs at the end of the phage genome and it is transcribed in the opposite direction of the lytic genes (Fig. S1B). Due to difficulty of detecting plaque-forming units (pfus) after treatment of $S$. pyogenes with ФAP1.1, we decided to determine if any of these four open reading 
frames (ORFs) inhibit the type II-A CRISPR-Cas response against phage infection in a Staphylococcus aureus heterologous system. To do this we inserted the S. pyogenes CEM1 $\triangle \Phi$ type II-A system into the lipase gene of $S$. aureus RNA4220 using the integrative vector pCL55 (Lee et al., 1991), generating strain JAV17. Additionally, we inserted a CRISPR locus with a spacer matching the gp68 gene from the staphylococcal phage ФNM4 $\gamma 4$ (Varble et al., 2019), generating JAV16 (Fig. S3B). JAV17 and JAV16 strains were transformed with each of the individual DAP1.1 ORFs under the control of an anhydrotetracycline (aTc)-inducible promoter, on the pJTR162 staphylococcal plasmid backbone (Rostol and Marraffini, 2019), with the exception of ORF3, for which we did not obtain transformants. Strains harboring the pJTR-ORF1, pJTR-ORF2 and pJTR-ORF4 constructs were then infected with ФNM4 $\gamma 4$ in the presence or absence of aTc, and pfus were counted (Fig. 3B). We found that none of the ORFs significantly affected the immunity of the JAV16 strain in the absence of the inducer, and ФNM4 $\gamma 4$ propagation was limited. In the presence of aTc, however, ORF2 expression enabled high levels of viral replication, similar to those observed in the absence of type II-A CRISPR-Cas immunity after infection of the JAV17 strain. ORF2 did not display amino-acid homology to previously identified Acrs, and therefore we named it AcrllA23, according to the current nomenclature (Bondy-Denomy et al., 2018). To corroborate that AcrlIA23 is active in $S$. pyogenes, we transformed strain CEM1 $\Delta \Phi$ with the streptococcal plasmid pLZ12 (Perez-Casal et al., 1991) or a version containing AcrllA23 under the control of an aTc inducible promoter, pLZ12-AcrlIA23. To measure type II-A immunity, each of these strains was then transformed with a second plasmid containing the spc5 target sequence, pTgt5, or an empty vector control, pC194, in the 
presence or absence of aTc (Fig. 3C). We found that in the absence of AcrllA23 expression there was low transformation efficiency for $\mathrm{pTgt5}$ and that this was reverted to the high levels observed for the non-target pC194 control by the addition of aTc. Altogether these results demonstrate that ФAP1.1 contains a novel inhibitor of the $S$. pyogenes CRISPR-Cas immune response.

AcrllA23 is required for $\Phi$ AP1.1 lysogenization under targeting conditions

To investigate the importance of AcrllA23 for ФAP1.1 lysogenization under targeting conditions, we generated a phage with a deletion of the inhibitor gene, ФAP1.1 ${ }^{\text {sacr23 }}$. We then infected strains CEM1 $\Delta \Phi$ and $\operatorname{CEM} 1 \Delta \Phi[\Delta 2-5]$ with the mutant virus and measured the formation of lysogens (Fig. 3B). We observed that, as opposed to the wild-type ФAP1.1, integration into the CRISPR array of strain CEM1 $\triangle \Phi$, but not in that of CEM1 $\Delta \Phi[\Delta 2-5]$, was markedly impaired. A similar decrease in lysogenization was detected when strain NTCT13743 was infected with the DAP1.1 $1^{\text {\acr23 }}$ phage (Fig. S3A). These results suggest that Cas9 cleavage of the phage genome in the absence of the inhibitor prevents lysogenization. To corroborate this, we isolated a ФAP1.1 $1^{\Delta a c r 23}$ virus that was able to escape targeting by $S$. pyogenes CEM $1 \Delta \Phi$ bacteria, which contained a mutation in the PAM sequence of the spc4 target (Fig. S1D) to escape Cas9 cleavage (Jinek et al., 2012; Nussenzweig et al., 2019). We then measured the lysogenization frequency of $\Phi A P 1.1^{\Delta a c r 23-e s c}$ and also found equally high levels of lysogen formation in the absence of the inhibitor (Fig. 3A). Importantly, as opposed to wild-type ФAP1.1, this mutant phage was capable of integrating its attL into DR6 and DRt (Fig. S4A, B) to 
produce lysogens in which the targeting spc4 crRNA is generated (Fig. S4C), providing efficient restriction of pTgt4 (Fig. S4D). Based on these results, we conclude that, through the inhibition of type II-A CRISPR-Cas targeting, AcrllA23 protects the phage during the early stages of infection, allowing ФAP1.1 integration into the CRISPR array.

acrllA23 transcription is turned off during $\Phi$ AP1.1 lysogenization

In spite of the presence of an active inhibitor of the type II-A CRISPR-Cas immune response, the ФAP1.1 prophage does not prevent plasmid targeting if the crRNA is still produced by the host (Fig. 2F). In addition, integration only occurs when immunity is neutralized by the deletion of the targeting spacers (Fig. S2D) or by the elimination of the crRNA guides they produce (Fig. 2G). In other words, AcrllA23 activity is not used to prevent "auto-immunity" against the prophage. This is a striking contrast to other Acrs found in prophages, which are expressed and active during both the lytic and lysogenic stages of infection (Bondy-Denomy et al., 2013; Stanley et al., 2019). We performed next-generation RNA sequencing (RNA-seq) to determine the pattern of expression of acrllA23. During the lytic cycle, we detected expression of a transcript spanning ORF1 and the inhibitor as early as 5 minutes after infection, continuing for at least 90 minutes and resulting in a constant increase of the mRNA levels (Fig. 4A). The same pattern is observed for a second transcriptional unit containing ORF3 and ORF4. In contrast, when we performed RNA-seq of a lysogen where ФAP1.1 was integrated into DR3, we found that only the ORF3-ORF4 mRNA is produced, while both the ORF1 and acrlIA23 genes are silenced (Fig. 4B). These results demonstrate that ФAP1.1 harbors a 
conditional inhibitor that is transcribed, and thus active, during the lytic but not during the lysogenic cycles of this temperate phage.

\section{Aberrant $Ф A P 1.1$ excision during prophage induction can transduce immunity}

In most of the strains sequenced to date, ФAP1.1-like phages are located in a spacerless CRISPR locus, flanked by a partial DR and a DR' (Fig. S1A). In our lysogenization experiments we observed that integration into a full CRISPR array can lead to spacer deletions (Figs. 1E, 2D, S2D). We hypothesized that the cycling between integration and excision could eventually lead to the elimination of all spacers and the prophage insertion pattern typically observed in sequenced genomes. To investigate this, we grew two CEM1 $\triangle \Phi(Ф A P 1.1)$ lysogens, with prophage insertions in DR3 and DR5, for 24 hours in liquid media containing mitomycin $\mathrm{C}(\mathrm{MMC})$ to trigger rounds of induction and integration. We then collected bacteria and amplified the attL and attR sites to detect changes in the number of spacers that flank each integration site. For the prophages originally inserted into DR3, we did not detect changes in the attL site, but the attR site appeared in PCR products of smaller sizes that indicated a location more proximal to the terminal repeat, either due to the deletion of spacer-repeat units, or re-insertion into repeats downstream of DR3 (Fig. 5A). Importantly, these new PCR products were diminished in the absence of MMC treatment, indicating that they did not arise from preexisting repeat-spacer deletions present in the culture, and are not an artifact of amplification. A similar result was obtained with the prophage originally inserted in DR5, for which we were able to detect a smaller product, whose size indicated integration of the attR site into the DR' (Fig. 5B). Moreover, amplification of the attP site of the phages 
induced with MMC produced a DNA fragment consistent with the size of an additional spacer-repeat unit, which was not seen when DNA from the ФAP1.1 stock was used as template (Fig. 5C). These results suggest that over evolutionary timescales multiple rounds of prophage integration and excision can lead to the eventual erasure of the CRISPR array observed in the natural isolates of ФAP1.1 lysogens.

The possibility that spacers are deleted during ФAP1.1 induction, raises the question of whether these spacers can become part of the viral genome during prophage excision. In principle, every DR and DR' contains both attR and attL sites (Figs. 1A) and therefore can be used by the phage integrase during excision. To determine if spacers can be excised along with the viral genome, CEM1 $\Phi$ (ФAP1.1) lysogens with the prophage integrated into DR3 (Figs. S5A) or DR5 (Figs. S5B) were induced with MMC, viral particles were purified from culture supernatants, and their DNA extracted to be used as template for spc1- (Fig. S5C) or spc2-specific (Fig. S5D) PCR assays. In all cases we found PCR products that indicated the presence of spacer-repeat units in the DNA of the viral particles, with the intensity of the amplicons indicating more spc1- than spc2containing viral particles. This suggested a possible preference for certain excision products. To obtain a more accurate representation of the population of spacer-carrying phages, we amplified the attP from the DNA of the purified phage particles collected after the MMC induction of prophages inserted into DR1-5. While the most prominent product consisted of the expected attP without any additional spacer-repeat units (Fig. 5C), we purified the DNA corresponding to larger amplicon sizes and subjected them to next generation sequencing to obtain the relative fraction of reads of each spacer (Fig. 5D). We observed a "proximity" effect, whereby the spacer sequences most commonly 
found in excised viral genomes were the closest to the DR in which the prophage was originally integrated; i.e., spc1 was the most commonly acquired spacer by phages previously residing in DR1 and DR2, spc1 and spc2 for DR3, and spc3 and spc4 for DR4 and DR5. This trend, however, was not perfectly uniform and therefore the results suggest that there are certain hotspots where attP formation is preferred. This was also reflected in the number of repeat-spacer units that were excised along with the prophage. Whereas prophages integrated into DR1 and DR2 typically contained a single unit, at least half of the reads of the DR3-5 lysogens contained two or more spacers (Fig. 5E).

The presence of repeat-spacer units in viral particles suggested that these could be added to the CRISPR array of new hosts following lysogenization (Fig. S5E). To test this, we induced with MMC CEM1 $\triangle \Phi(\Phi A P 1.1)$ lysogens in which the prophage was integrated into DR3, DR4, DR5 or a non-lysogen as a control. Viral particles were filtered from the culture supernatants and used to infect strain K56. Lysogens that survived superinfection were collected after five hours and their genomic DNA was extracted to use as template for spacer-specific PCR assays. We used primers that anneal outside of K56 CRISPR array, in the 5' or 3' flanking regions, in combination with primers that anneal to either the top or bottom strand of spc1 or spc3 sequences from the CEM1 $\triangle$ Ф CRISPR locus (Fig. S5E). Amplification resulted in many different products for each lysogen population with different numbers and combinations of repeat-spacer units (Fig. 5F). This was most likely a consequence of the presence of several repeat sequences in both phage and bacterial genomes, each being a suitable attP and attB site, respectively, thus multiplying the possibilities for integration (Fig. 
S5E). From this data we conclude that all of the three ФAP1.1 populations were able to transduce $s p c 1$ and $s p c 3$ from the CEM1 $\Delta \Phi$ strain into the CRISPR locus of the K56 strain. Sanger sequencing of PCR products obtained after transduction with a ФAP1.1 prophage previously integrated in the DR3 of CEM1 $\triangle \Phi$, confirmed this conclusion (Fig. $5 F)$.

\section{Discussion}

Here we describe the interaction between the temperate phage ФAP1.1 and the type IIA CRISPR-Cas system of its host, S. pyogenes. Uniquely, this phage uses the CRISPR DR sequence as the attachment site for integration and expresses an anti-CRISPR, AcrllA23, that it is only active during the lytic portion of its replication cycle. This unique mode of insertion generates a very complex and rich molecular interplay between the virus and CRISPR immunity. Integration disrupts the transcription of the crRNAs located downstream of the prophage and eliminates the portion of the repeat sequence important for crRNA maturation of the spacer immediately upstream of the attL. However, the transcription of spacers further upstream and of the cas genes (in all $S$. pyogenes strains sequenced to date the cas operon is located upstream of the type II-A CRISPR array) is not altered. As a consequence of this, ФAP1.1 integration can selectively turn off the immunity provided by different sets of spacers (Fig. 2F). This differs from the mode of action of previously described anti-CRISPRs that broadly turn off CRISPR function (Davidson et al., 2020), and can provide a selective advantage for ФAP1.1 (and related phages), which could exploit integration to neutralize spacers that target its genome, but at the same time maintain the immunity provided by other 
spacers against competitor phages, promoting host survival. Additionally, these lysogens could also retain the ability to acquire new spacers in the first position of the CRISPR array against new invaders. Furthermore, due to the presence of multiple attL and attR sites, one in every upstream and downstream DR, respectively, induction of the ФAP1.1 prophage can result in the incorporation of repeat-spacer units into the viral genome. We observed that different spacer-repeat units were excised along ФAP1.1 genome at different levels, and therefore we speculate, as it is the case for the att sites of other temperate phages, that the excision of the attR and attL elements is influenced by its flanking sequences, which would be the CRISPR spacers in the case of ФAP1.1. Once in the viral genome, repeat-spacer units have the possibility to be transduced into a different $S$. pyogenes strain and, depending on their position relative to the prophage, provide new immunity to the recipient cell (Fig. 5F). Such spacer transduction events would increase the range of viral targets in the CRISPR system in an adaptationindependent manner, and benefit both the residing prophage and its host. In contrast, we and others have previously reported transduction of entire CRISPR systems (Varble et al., 2019; Watson et al., 2018), which is enhanced by recombination between targeting spacers in the CRISPR array and the phage genome. While this phenomenon is due to the promiscuity of phage recombinases, ФAP1.1-mediated transduction of spacers appears to be a specifically evolved interaction that intertwines the phage lifecycle with the CRISPR locus.

S. pyogenes prophages carry virulence genes that play fundamental roles in the different manifestations of group A streptococcus (GAS) disease (Banks et al., 2002). Both the gain- and loss-of-function of spacers that result from integration of ФAP1.1 into 
the CRISPR array could play an important role in the restriction or tolerance of prophages targeted by type II-A immunity. Therefore, we believe that the diversity of spacer genotypes generated during the interplay between ФAP1.1 phages and their hosts, even if occurring at a very low frequency, could lead to the selection of prophagedependent phenotypes that enable specific $S$. pyogenes adaptations, including the modulation of its virulence. However, in most of the $S$. pyogenes strains sequenced so far, ФAP1.1-related prophages are integrated into a single DR' element (Fig. S1A). We suggest that after the initial insertion into a full CRISPR array, subsequent rounds of excision and integration lead to the selection of spacer deletions that ultimately erase all repeat-spacer units. This would cause an irreversible inhibition of the type II-A CRISPRCas immune response, since the single DRt that can be re-formed after prophage excision does not support spacer acquisition (data not shown). Thus, it seems that from all the possible ФAP1.1 lysogens that can be formed, natural selection has favored those that lack type II-A anti-phage immunity. We hypothesize that this decreases barriers against viral infection, facilitating the incorporation of the multiple prophages, and therefore allowing lateral gene flow that plays a critical role for $S$. pyogenes survival and colonization of the human host.

While ФAP1.1 integration can neutralize CRISPR immunity, inhibition only occurs after lysogenization. Therefore, the phage could be susceptible to Cas 9 cleavage during genome injection if there is a targeting spacer in the type II-A CRISPR array. To prevent this, ФAP1.1 expresses an inhibitor, AcrllA23, immediately after infection. Transcription of the anti-CRISPR, however, is completely turned off after prophage integration. This is in contrast to other Cas9 inhibitors, which remain active in the lysogen. Indeed, the first 
acrllA genes were discovered after the identification of type II-A CRISPR systems harboring seemingly inactive spacers with perfect targets in residing prophages of Listeria (Rauch et al., 2017). This is also the case for acrl genes carried by Pseudomonas prophages, which are able to inhibit the type I CRISPR response (Bondy-Denomy et al., 2013). Following robust transcription at the onset of phage infection, acr genes are repressed by anti-CRISPR associated (Aca) transcription factors to prevent the deleterious effects of the acr high transcription on the downstream phage genes (Osuna et al., 2020; Stanley et al., 2019). The acr region of ФAP1.1 contains two genes, orf3 and orf4, which are transcribed during lysogeny. Since aca genes are invariably found in the vicinity of acr genes (Marino et al., 2018; Stanley et al., 2019; Yin et al., 2019), we hypothesize that orf3 or orf4 produce the Aca that regulates transcription of acrllA23, providing a tight repression that is not observed in other lysogens that produce basal levels of inhibitor. Regardless of the mechanism that prevents acrllA23 transcription in ФAP1.1 lysogens, the absence of Cas9 inhibition after integration only selects prophage insertions that prevent the generation of the targeting crRNA. In summary, our study presents a unique dynamic in the parasite-host conflict, where the phage can modulate the CRISPR immunity of streptococci to protect itself from targeting, while still allowing the defense of the lysogen against other invaders. 
Acknowledgements. We thank Pascal Maguin and Alexander J Meeske for bioinformatic assistance with the RNA-seq analysis. Support for this work comes from the National Institute of Health Director's Pioneer Award 1DP1GM128184-01 and the Burroughs Wellcome Fund PATH Award to LAM. LAM is an Investigator of the Howard Hughes Medical Institute. AV was supported by the Arnold and Mabel Beckman Postdocotoral Fellowship. JTR is supported by the Boehringer Ingelheim Fonds PhD fellowship.

Author contributions. AV and LAM conceived the study. EC, CWE, and VAF aided with experimental design. AV performed all the experiments with the help of JF. EC assisted with bioinformatic analysis and EC and CWE provided assistance, strains and reagents for $S$. pyogenes experiments. JTR provided reagents. AV and LAM wrote the manuscript with the help of the other authors.

Competing interests. LAM and AV are co-inventors on a patent application filed by The Rockefeller University relating to work in this study. LAM is a founder and advisor of Intellia Therapeutics and Eligo Biosciences. 


\section{Figure Legends}

Figure 1. ФAP1.1 lysogenization into the CRISPR locus. (A) Recombination between the attP site of $\Phi A P 1.1$ (orange) and the attB site present in the direct repeat (DR, black) of $S$. pyogenes type II-A CRISPR loci. The mutations of the terminal repeat (DRt) are shown in grey. Recombination results in prophage integration and the generation of att $L$ and attR sites that will recombine during prophage induction and excision. (B) Type II-A CRISPR-cas locus of S. pyogenes K56, showing DR1 and DR2 and DRt as white or grey boxes; spacers as colored boxes. Orange arrowheads indicate the three possible integration sites of ФAP1.1 in the different repeats. Arrows indicate the primers that anneal on the host (black) or phage (orange) genome to amplify the resulting the attL or attR sites. (C) Agarose gel electrophoresis of the attL or attR PCR products obtained after the amplification shown in (B). Orange arrowheads indicate the inferred integration sites. (D) Frequency of lysogens $(n=100)$ carrying attL or attR sites in each of the DRs of the K56 CRISPR locus. (E) Frequency of lysogens $(n=100)$ carrying different number of spacers. (F) Same as (D) but showing the combined distribution of attL or attR sites.

Figure 2. Disruption of CRISPR function by $\Phi$ AP1.1 lysogenization. (A) $S$. pyogenes CEM1 $\triangle \Phi$ type II-A CRISPR-cas locus, wild-type and the mutant lacking spacer-repeat units 2, 3, 4 and 5, [ $\Delta 2-5]$. (B) Transformation efficiency of the pC194 plasmid or a modified version harboring a target for spc4 from ФAP1.1, pTgt4, after electroporation of wild-type or [ $\Delta 2-5] S$. pyogenes CEM $1 \Delta \Phi$ competent cells. Mean + STD of 3 biological replicates are reported. (C) Frequency of lysogens $(n=100)$ carrying att $L$ or attR sites in each of the DRs of the CEM1 $\triangle \Phi$ CRISPR locus. (D) Frequency of lysogens $(n=100)$ carrying different number of spacers. (E) Same as (C) but showing the combined distribution of attL or attR sites. (F) Transformation efficiency (relative to a pC194 vector control) of plasmids harboring targets for spc4, spc1 or spc5 (pTgt4, pTgt1, pTgt5, respectively) after electroporation of wild-type or lysogenic $S$. pyogenes CEM1 $\triangle \Phi$ competent cells. The $\Phi A P 1.1$ integration site for each lysogen is indicated. Mean + STD of 3 biological replicates are reported. (G) Northern blot analysis of spc4, $s p c 1$ and spc5 crRNAs, as well as 5S rRNA, produced by the strains transformed in (F).

Figure 3. ФAP1.1 carries a type II-A CRISPR-Cas inhibitor, AcrllA23. (A)

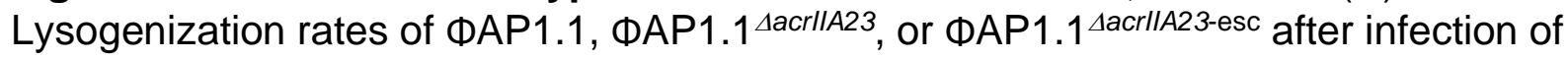
wild-type or $[\Delta 2-5]$ S. pyogenes CEM1 $\Delta \Phi$ cells. Mean + STD of 3 biological replicates are reported. (B) Efficiency of plaquing of phage $\Phi N M 4 \gamma 4$ on soft agar lawns of $S$. aureus JAV17 or JAV16, in the presence or absence of aTc, carrying the pJTR162 control plasmid or versions that express the different ORFs of the ФAP1.1 anti-CRISPR locus. Mean + STD of 3 biological replicates are reported. (C) Transformation efficiency of the $\mathrm{pC} 194$ plasmid or a modified version harboring a target for spc5, pTgt5, after electroporation of $S$. pyogenes CEM1 $\triangle \Phi$ competent cells carrying the pLZ12 vector or a version expressing AcrllA23 under the control of a tetracycline-inducible promoter, in the presence or absence of aTc. Mean + STD of 3 biological replicates are reported.

Figure 4. AcrllA23 is not transcribed from ФAP1.1 prophages. (A) RNAseq of $S$. pyogenes CEM1 $\triangle \Phi$ cells at different times after infection with $\Phi A P 1.1$. The fraction of reads (relative to the total number of reads) that map to the acr region of the phage are 
plotted. (B) Same as $(\mathbf{A})$ but using RNA from a culture of $S$. pyogenes CEM1 $\Delta \Phi$ (ФAP1.1::DR3) lysogen.

Figure 5. ФAP1.1 mediates the transduction of CRISPR spacers. (A) Agarose gel electrophoresis of the attL or attR PCR products obtained after treatment of $S$. pyogenes CEM1 $\triangle \Phi(\Phi A P 1.1:: D R 3)$ lysogens with mitomycin C (MMC). Primers used and the expected products are shown in the diagrams to the right. Black arrowheads indicate PCR products that lack a number of the expected spacer-repeat units. (B) Same as $(\mathbf{A})$ but after treatment of $S$. pyogenes CEM1 $\Phi$ (ФAP1.1::DR5) lysogens. (C) Same as $(\mathbf{A})$ but after amplification of the ФAP1.1 attP site. "s" indicates a control amplification of a phage stock that has never been lysogenized. (D) DNAseq of the attP amplification products obtained via PCR after induction of ФAP1.1 prophages integrated in the indicated DR. The fraction of reads (relative to the total reads) corresponding to each spacer sequence associated with the attP site is shown. (E) Distribution of the number of spacers associated with the attP in (D). (F) Agarose gel electrophoresis of PCR products obtained from the amplification of the CRISPR locus of S. pyogenes K56 lysogens generated after infection with lysates obtained from $S$. pyogenes CEM1 $\triangle \Phi$ lysogens where ФAP1.1 was integrated into DR3, DR4, DR5 or DR1-t (lacking all spacers). Top diagram shows the K56-, spc1- or spc3-specific primers used as black, red or green arrows, respectively. Diagrams next to gels show the spacer composition of 14 different PCR products that were sequenced, obtained after transduction of $S$. pyogenes CEM1 $\triangle$ (ФAP1.1::DR3) lysates.

Figure S1. ФAP1.1 integration into S. pyogenes type II-A CRISPR loci. (A) ФAP1.1like phages integrated into the type II-A CRISPR locus of $S$. pyogenes strains. (B) Schematic of the ФAP1.1 genome. Targets for the spacers found in different strains are shown on top or bottom depending on the phage DNA strand that is targeted. The acr region and its four ORFs are highlighted in grey. The aadA gene inserted to confer spectinomycin resistance to ФAP1.1 lysogens is shown in light blue. (C) Spacer duplication events observed in $S$. pyogenes K56(ФAP1.1) lysogens. (D) Sequences of the $S$. pyogenes CEM1 $\Phi$ spc4 crRNA annealed to its targets in ФAP1.1 and ФAP1.1 1 acrllA23-esc. The PAM nucleotides are boxed. The escape mutation of DAP1.1 4 acrllA23-esc is in red.

Figure S2. ФAP1.1 lysogenization into the S. pyogenes NCTC13743 type II-A CRISPR locus. (A) S. pyogenes NTCT13743 type II-A CRISPR-cas locus, wild-type and the mutant lacking spacer-repeat units 1 through 10, [ $\Delta 1-10]$. (B) Sequences of the S. pyogenes NTCT13743 spc2, spc6 and spc9 crRNAs annealed to their targets in ФAP1.1. The PAM nucleotides are boxed. (C) Transformation efficiency of the pC194 plasmid or a modified version harboring the three targets for $s p c 2, s p c 6$ and $s p c 9$, pTgt2-6-9 from ФAP1.1, after electroporation of wild-type or [ $\Delta 1-10] S$. pyogenes NCTC13743 competent cells. Mean + STD of 3 biological replicates are reported. (D) Diagrams of the type II-A locus of 25 DAP1.1 lysogens in S. pyogenes NCTC13743, reconstructed after sequencing of their att $L$ and att $R$ sites.

Figure S3. AcrllA23 inhibits the type II-A CRISPR-Cas response in S. pyogenes NCTC13743 and S. aureus RN4220. (A) Lysogenization rates of ФAP1.1 or 
ФAP1.1 $1^{\Delta a c r l I A 23}$ after infection of wild-type or [ $\left.\Delta 1-10\right] S$. pyogenes NCTC13743 cells. Mean + STD of 3 biological replicates are reported. (B) Integration of the type II-A CRISPR locus of $S$. pyogenes into the lipase gene (geh) of $S$. aureus RN4220, generating strain JAV17. Integration of a locus containing a spacer targeting the staphylococcal phage $\Phi$ NM4Y4 generates strain JAV16.

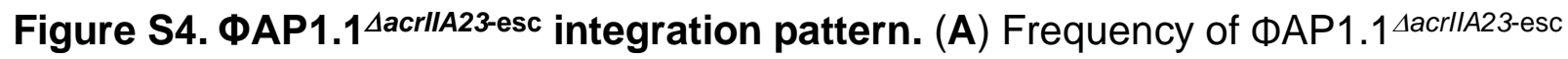
lysogens $(n=50)$ carrying attL or attR sites in each of the DRs of the CEM1 $\triangle$ CRISPR locus. (B) Same as (A) but showing the combined distribution of attL or attR sites. (C) Northern blot analysis of spc4 crRNAs, as well as $5 S$ rRNA, produced by wild-type $S$. pyogenes CEM1 $\triangle$ Ф or its different ФAP1.1 (DR1-5, 1-t) or ФAP1.1 ${ }^{\Delta a c r l l A 23-e s c}$ (DR6, DRt) lysogens. (D) Transformation efficiency of the $\mathrm{pC} 194$ plasmid or a modified version harboring a target for spc4 from ФAP1.1, pTgt4, after electroporation of the strains used in (C). Mean + STD of 3 biological replicates are reported.

Figure S5. ФAP1.1-mediated transduction of spacers from the CEM1 $\Delta \Phi$ to the K56 CRISPR locus. (A) Example of incorrect $\Phi A P 1.1$ excision in S. pyogenes CEM1 $\triangle \Phi$ (ФAP1.1::DR3) lysogens, where DR1 or DR2 are used instead of attL for recombination with attR. ФAP1.1-, spc1- and spc2-specific primers used to detect expanded attP sites are shown as orange, red and yellow arrows, respectively. (B) Same as (A) but for a ФAP1.1::DR5 lysogen. (C) Agarose gel electrophoresis of PCR products obtained after the amplification of the attP site of $\triangle A P 1.1$ phages induced with MMC from ФAP1.1::DR3, ФAP1.1::DR5 and ФAP1.1::DR1-t lysogens, using spc1-specific primers. (D) Same as (C) but using spc3-specific primers. (E) Example of possible recombination

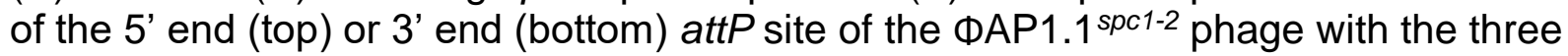
attB sites present in the DR1, DR2 and DRt of $S$. pyogenes K56. 


\section{Methods}

\section{Bacterial strains and growth conditions}

Culture of $S$. pyogenes and $S$. aureus was carried out in brain-heart infusion (BHI) medium at $37^{\circ} \mathrm{C}$. For $S$. pyogenes, liquid experiments were carried out in 10 milliliters of medium in $15 \mathrm{ml}$ conical tubes unless otherwise noted. S. pyogenes media was supplemented with $5 \mu \mathrm{g} / \mathrm{ml}$ chloramphenicol or $50 \mu \mathrm{g} / \mathrm{ml}$ spectinomycin for plasmid maintenance and/or lysogen selection. For $S$. aureus, liquid experiments were carried out in 3 milliliters of medium in $15 \mathrm{ml}$ conical tubes. S. aureus media was supplemented with $5 \mu \mathrm{g} / \mathrm{ml}$ chloramphenicol or $10 \mu \mathrm{g} / \mathrm{ml}$ erythromycin for plasmid maintenance and/or strain selection. All strains used in this study are listed in Table S1.

\section{Induction of Lysogens}

To isolate phage, overnight cultures of the indicated lysogens were diluted 1:50 into 10 $\mathrm{mls}$ of $\mathrm{BHI}$ and grown at $37^{\circ} \mathrm{C}$ without agitation. At $\mathrm{OD}_{600}=0.3$ cells were induced with $0.5 \mu \mathrm{g} / \mathrm{ml}$ of mitomycin C. Four hours post-induction cells were spun down and supernatant was filtered through $0.45-\mu \mathrm{m}$ syringe filters (Acrodisc).

\section{Strain construction}

To make S. aureus strains with the integrated SF370 CRISPR locus (JAV17 and JAV16, Table S1), pCL55-integration plasmids were constructed containing the SF370 cas genes with the wildtype CRISPR array (pAV121) or with a CRISPR array containing a ФNM4 4 4-targeting spacer (pAV122) ( 5'-

TGATACATTAACATTTAGTAAATCATTACG -3'). These vectors were transformed in RN4220, recovered at $30^{\circ} \mathrm{C}$ for 2 hours, and plated on $5 \mu \mathrm{g} / \mathrm{ml}$ chloramphenicol. Integration was confirmed using primers oGG50 and oGG96.

Deletions of spacers in S. pyogenes strains CEM and NCTC 13743 were isolated by curing lysogens ФAP1.1-spec. Prophages were cured by transforming lysogens as described in the transformation assay section with a plasmid containing the SF370 type II-A cas 9 with a CRISPR array targeting the ФAP1.1-spec, pAV315 (5'-

TATATTTGGTGTGAAAGAAAGAAGCACATG -3'). Following transformation, clones were isolated and CRISPR arrays were screened using primers AV1171 and AV1015 to detect spacer deletions. Positive clones were then passaged without selection for two $1: 100$ dilutions and patched on plain and chloramphenicol plates to isolate clones that had lost the targeting plasmid.

\section{Phage construction}

To create DAP1.1-spec, the K56 strain of $S$. pyogenes was transformed with pAV329, a plasmid containing spectinomycin resistance cassette and $\sim 1$ kilobase phage-homology arms, to insert the antibiotic resistance cassette immediately downstream the phage integrase in the lysogeny region. This strain was diluted 1:50 into $10 \mathrm{mls}$ of $\mathrm{BHI}$ and supplemented with $5 \mathrm{mM} \mathrm{CaCl} 2$ and grown at $37^{\circ} \mathrm{C}$ without agitation and infected with $\Phi A P 1.1$ at $\mathrm{OD}_{600}=0.3$. The resulting lysate was filtered through $0.45-\mu \mathrm{m}$ syringe filters (Acrodisc) and used to infect K56. Five hours post infection cells were plated on 50 $\mu \mathrm{g} / \mathrm{ml}$ spectinomycin. Insertion of the spectinomycin cassette into ФAP1.1 was confirmed using primers AV1277 and AV1298. 
Isolation of ФAP1.1 $1^{\Delta a c r 23}$ deletion was isolated by passaging $\Phi A P 1.1-s p e c$ on a CEM strain containing a plasmid expressing a type III-A CRISPR-Cas system from $S$. epidermidis with a spacer targeting acrlIA23 (5'-

ATATTCCATTTTATTTCTCCTTATTACATAGATAA-3', pAV449). $300 \mu$ l of overnight cultures of CEM $\Delta \Phi[\Delta 2-5]$ transformed with pAV392 mixed with $5 \mathrm{ml}$ of $50 \% \mathrm{BHI}$ agar supplemented with $5 \mathrm{mM} \mathrm{CaCl} 2$ and infected ФAP1.1-spec. Escaper plaques were isolated and replaqued on this strain. Phage DNA was isolated and primers AV1339 and 1340 were used to amplify the targeted region. A phage was isolated with a deletion spanning nucleotide 37,881 to 39,044 of the ФAP1.1-spec genome, encompassing acrllA23 and orf1.

Isolation of ФAP1.1 ${ }^{\Delta a c r 23-e s c}$ escaping from spacer 4 targeting of SF370 CRISPR array was carried out by passaging $\Phi A P 1.1^{\Delta a c r 23}$ on a CEM strain containing a plasmid expressing a type II-A CRISPR spacer (pAV392). Spacer 4 from SF370 contains a mismatch at position 8 when targeting the ФAP1.1, which was corrected in the spacer cloned into pAV392 to perfectly target ФAP1.1. $300 \mu$ l of overnight cultures of $\mathrm{CEM} \Delta \Phi[\Delta 2-5]$ transformed with pAV392 mixed with $5 \mathrm{ml}$ of $50 \% \mathrm{BHI}$ agar supplemented with $5 \mathrm{mM} \mathrm{CaCl}_{2}$ and infected ФAP1.1 ${ }^{\Delta a c r 23}$. Escaper plaques were isolated and replaqued on this strain. Phage DNA was isolated and primers AV1127 and AV1128 were used to amplify the spacer 4 target region and a phage with a $G$ to $A$ mutation in the first PAM position was isolated for subsequent experiments.

\section{Phage Sequencing}

ФAP1.1-spec DNA was purified as previously described (Varble et al., 2019). Phage DNA was sheared to 300 base pairs using the Covaris Ultrasonicator S220. Sheared DNA was prepped using the TruSeq Nano kit (Illumina) and and was sequenced using 150-nucleotide single-end read with an Illumina MiSeq. The phage genome was assembled using SPAdes (Bankevich et al., 2012) and the phage cos site was predicted using PhageTerm (Garneau et al., 2017).

\section{Quantification of Lysogens}

To quantify lysogens, the indicated strain was diluted 1:30 into BHI supplemented with 5 $\mathrm{mM} \mathrm{CaCl}_{2}$. At $\mathrm{OD}_{600}=0.3$, cultures were infected with $50 \mu \mathrm{l}$ of ФAP1.1-spec. Cells were harvested 90 minutes post infection and plated on $\mathrm{BHI}$ plates with $50 \mu \mathrm{g} / \mathrm{ml}$ spectinomycin. Individual colonies were restreaked and genomic DNA was isolated by resuspending colonies in colony lysis buffer $(250 \mathrm{mM} \mathrm{KCl}, 5 \mathrm{mM} \mathrm{MgCl} 250 \mathrm{mM} \mathrm{Tris-HCl}$ at $\mathrm{pH}$ 9.0, 0.5\% Triton X-100) supplemented with 500U PlyC (Nelson et al., 2006) and incubated at $37^{\circ} \mathrm{C}$ for 20 minutes, then $98^{\circ} \mathrm{C}$ for 10 minutes. Samples were centrifuged and supernatant was used for PCR amplification with primers $\mathrm{H} 237$ and AV1050 for the attL junction and AV1089 and AV1015 for the attR junction.

\section{Lysogen passaging}

ФAP1.1-spec lysogens integrated into the indicated direct repeat (DR) of CEM1 $\triangle \Phi$ were inoculated from single colonies and serially passaged by making 1:100 dilutions after 24 hours of growth. Half were passaged in the presence of a sub-lethal concentration of mitomycin $C(0.1 \mu \mathrm{g} / \mathrm{ml})$.

\section{Efficiency of plaquing assays}


For $S$. aureus, phage titer assays were performed as previously described(Goldberg et al., 2014). Briefly, S. aureus strains with either the wildtype integrated type II-A locus from SF370 (JAV17) or the locus with a ФNM4Y4 targeting spacer (JAV16, 5'-

TGATACATTAACATTTAGTAAATCATTACG-3') were transformed with either a CtI vector (pJTR162), orf4 (pAV412), AcrlIA23 (pAV413), or orf1 (pAV414). Strains were outgrown for 2 hours. 30 minutes pre-collection aTc was added at a concentration of $12.5 \mathrm{ng} / \mathrm{ml} .200 \mu \mathrm{l}$ of cultures were mixed with $5 \mathrm{ml}$ of $50 \% \mathrm{BHI}$ agar supplemented with $5 \mathrm{mM} \mathrm{CaCl}_{2}$. Cells were plated on plain plates or plates supplemented with aTc. Serial dilutions of $\Phi$ NM4 44 were then spotted on the plates.

\section{Cell Transformations}

For $S$. aureus, transformations were carried out as previously described (Goldberg et al., 2014). For S. pyogenes, overnight cultures were diluted 1:50 into $250 \mathrm{mls}$ of BHI and grown at $37^{\circ} \mathrm{C}$ without agitation. At $\mathrm{OD}_{600} 0.3-0.4$, cultures were pelleted and washed three times with cold $10 \%$ glycerol. Plasmid DNA was prepped from Staphylococcus aureus strain RN4220 (Kreiswirth et al., 1983), and dialyzed on 0.025 $\mu \mathrm{m}$ nitrocellulose filters (Millipore). $100 \mathrm{ng}$ of DNA was added to $50 \mu \mathrm{l}$ aliquots of electrocompetent cells and transformed in cold $1 \mathrm{~mm}$ cuvettes under the following settings: $2500 \mathrm{~V}, 25 \mu \mathrm{F}, 600 \Omega, 1 \mathrm{~mm}$. After electroporation cells were resuspended in $950 \mu \mathrm{l}$ of $\mathrm{BHI}$ and recovered at $37^{\circ} \mathrm{C}$ without agitation for two hours.

\section{Transformation Assays}

For $S$. pyogenes, cells were prepped as described in cell transformation section. The plasmids used for targeting experiments were Ctl (pC194), Spacer 1 target (pAV344), Spacer 4 target as it appears in ФAP1.1 (pAV354), Spacer 5 target (pAV346), and the three potential NCTC 13743 targets as they appear in ФAP1.1 (pAV407). $100 \mathrm{ng}$ of DNA was added to $50 \mu$ laliquots of electrocompetent cells and transformed in cold 1 mm cuvettes under the following settings: $2500 \mathrm{~V}, 25 \mu \mathrm{F}, 600 \Omega, 1 \mathrm{~mm}$. After electroporation cells were resuspended in $950 \mu \mathrm{l}$ of $\mathrm{BHI}$ and recovered at $37^{\circ} \mathrm{C}$ without agitation for two hours. Serial dilutions were then made and plated on the appropriate antibiotics. For cultures where AcrllA23 was expressed, cells transformed with Ctl (pLZ12spec) and AcrlIA23 (pAV432) were grown as above, with anhydrous tetracycline (aTc) added 30 minutes pre-collection at $12.5 \mathrm{ng} / \mathrm{ml}$. Cells were treated as above and plated on the appropriate antibiotics plus or minus aTc.

\section{RNA isolation}

Overnight cultures were diluted 1:50 into $100 \mathrm{mls}$ of $\mathrm{BHI}$ and grown at $37^{\circ} \mathrm{C}$ without agitation. At OD 600 0.3-0.4, cultures were pelleted. Cells were resuspended in $70 \mu \mathrm{l}$ of PBS supplemented with 500U PlyC (Nelson et al., 2006) and incubated at $37^{\circ} \mathrm{C}$ for 30 minutes with shaking. $10 \mu \mathrm{l}$ of $10 \%$ sarkosyl was then added and sample was then vortexed. RNA was then purified and DNase treated using isolated using the Direct-zol miniprep plus kit (Zymo Research) for RNA-seq or with TRIzol for Northern blots.

\section{Small RNA Northern blots}

Northern blot analysis was carried out as previously described (Pall and Hamilton, 2008). $20 \mu \mathrm{g}$ of purified RNA was loaded. AV1149 was used to blot for spacer 1 , 
AV1152 for spacer 4, AV1153 for spacer 5, and AV1156 for 5S. Primers used in this study are detailed in Supplementary Table S2.

\section{RNA sequencing}

For phage infection time courses, overnight cultures of $S$. pyogenes strain CEM were diluted 1:50 into $10 \mathrm{mls}$ of $\mathrm{BHI}$ and grown at $37^{\circ} \mathrm{C}$ without agitation. At OD 6000.3 cells were infected with ФAP1.1-spec and were pelleted and frozen at indicated time points. RNA was then isolated as described above. For lysogen sequencing an overnight culture of CEM with ФAP1.1-spec integrated into direct repeat 3 was diluted 1:50 into 10 $\mathrm{mls}$ of $\mathrm{BHI}$ and grown at $37^{\circ} \mathrm{C}$ without agitation. At OD 6000.3 , RNA was harvested as described as above. Ribosomal RNA was depleted using Ribo-Zero Plus rRNA Depletion Kit (Illumina) and subsequently purified using the RNA Clean and Concentrate -5 kit (Zymo Research). RNA was then prepped for deep-sequencing using the TruSeq Stranded mRNA Library Preparation Kit (Illumina) and run on the MiSeq System (Illumina). Reads were aligned to the ФAP1.1-spec genome for the phage time course or the ФAP1.1-spec genome integrated into direct repeat 3 of the CEM1 $\triangle$ CRISPR array using Bowtie 2 (Langmead and Salzberg, 2012). SAM files were normalized by total read count and converted to WIG files with a custom python script to plot coverage at each nucleotide. For the phage infection time course reads were mapped from nucleotide 35,754 to 39,363 of the ФAP1.1-spec genome. For lysogen sequencing reads were mapped to this region plus the 286 base pairs of the 3' portion of the CRISPR array.

\section{Characterizing phage attP}

To isolate phage carrying spacers from the CEM1 $\Phi$ CRISPR array, overnight cultures of the indicated lysogens were diluted 1:50 into $10 \mathrm{mls}$ of $\mathrm{BHI}$ and grown at $37^{\circ} \mathrm{C}$ without agitation. At OD $600=0.3$ cells were induced with $0.5 \mu \mathrm{g} / \mathrm{ml}$ of mitomycin $\mathrm{C}$. Four hours post-induction cells were spun down and supernatant was filtered through $0.45-$ $\mu \mathrm{m}$ syringe filters (Acrodisc). Phage DNA was purified from these inductions as previously described (Varble et al., 2019). From purified DNA, specific PCRs were carried out for spacer 1, 2 and 5. For spacers 1 and 2, AV1089 was used as the forward primer, while AV1149 and AV1151 were used as reverse primers for spacer 1 and 2 respectively. For spacer 5, H57 was the spacer 5-specfic forward primer, while AV1008 was the reverse primer. To deep sequence the phage att $P$, the phage junction was amplified from purified phage particles with AV1169 and AV1170, products above the typical 75-nucleotide phage attP were gel purified and prepped for deep-sequencing with the TruSeq Nano kit (Illumina). DNA was sequenced using 150-nucleotide singleend read with an Illumina MiSeq. A custom python script was used to quantify spacers in the phage attP, with read length limiting the detection of spacers in the att $P$ to two.

\section{Detection of spacer transfer}

Phage carrying spacers from the CEM1 $\triangle \Phi$ CRISPR array were isolated as described in the characterizing attP section. $S$. pyogenes strain $\mathrm{K} 56$ was diluted 1:30 into 10 mls of $\mathrm{BHI}$ and supplemented with $5 \mathrm{mM} \mathrm{CaCl}_{2}$ and grown at $37^{\circ} \mathrm{C}$ without agitation. At $\mathrm{OD}_{600}$ $=0.3$ cells were infected with phage induced from the indicated direct repeat. Cells were harvested five hours post infection. Genomic DNA was isolated using the Wizardß Genomic DNA Purification kit (Promega). Cells were resuspended in $100 \mu \mathrm{l}$ of $50 \mathrm{mM}$ 
EDTA with $500 \mathrm{U}$ PlyC and incubated at $37^{\circ} \mathrm{C}$ with shaking for 30 minutes. $600 \mu \mathrm{l}$ of Nuclei lysis solution was then added and DNA was purified following the manufacturer's instructions. PCRs were then carried out to detect transfer of transfer of spacers either $5^{\prime}$ or $3^{\prime}$ of the integrated lysogen in K56. For the amplification of 5' spacers, AV1171 was the forward primer, while AV1149 and AV1151 were used to specifically detect CEM1 $\triangle \Phi$ spacer's one and three, respectively. For the amplification of 3' spacers, AV1015 was the reverse primer, while $\mathrm{H} 49$ and $\mathrm{H} 53$ were used to specifically detect CEM1 $\Delta \Phi$ spacer's one and three, respectively.

\section{Plasmid construction}

Table S3 contains the information of the primers, templates and DNA fragments used to construct all the plasmids in this study.

\section{Next generation sequencing data}

Next-generation sequencing data used to generate Figures $4 \mathrm{~A}, 4 \mathrm{~B}, 5 \mathrm{D}$ and $5 \mathrm{E}$ is deposited under BioProject accession number PRJNA668016. 


\section{Supplementary Tables.}

\section{Supplementary table S1. Strains used in this study.}

\begin{tabular}{|c|c|c|}
\hline Strains & Description & Reference \\
\hline K56 & S. pyogenes strain & (Kjems, 1958) \\
\hline SF370 & S. pyogenes strain with spacer targeting & $\begin{array}{l}\text { (Ferretti et al., } \\
\text { 2001) }\end{array}$ \\
\hline $\mathrm{CEM} 1 \Delta \Phi$ & S. pyogenes strain, SF370 with no prophages & $\begin{array}{l}\text { (Euler et al., } \\
2016 \text { ) }\end{array}$ \\
\hline $\mathrm{CEM} 1 \Delta \Phi[\Delta 2-5]$ & S. pyogenes strain CEM1 $\Delta \Phi$ with spacers $2-5$ deleted & This study \\
\hline NCTC13743 & S. pyogenes strain & $\begin{array}{l}\text { Accession no. } \\
\text { SAMEA3879489 }\end{array}$ \\
\hline $\operatorname{NCTC} 13743[\Delta 1-10]$ & S. pyogenes strain NCTC 13743 with spacers 1-10 deleted & This study \\
\hline RN4220 & S. aureus strain & $\begin{array}{l}\text { (Kreiswirth et } \\
\text { al., 1983) }\end{array}$ \\
\hline JAV16 & S. aureus strain with integrated SF370 type II-A CRISPR targeting $\Phi N M 4 \gamma 4$ & This study \\
\hline JAV17 & S. aureus strain with integrated S. pyogenes type II-A CRISPR & This study \\
\hline ФAP1.1 & S. pyogenes phage & This study \\
\hline ФAP1.1-spec & ФAP1.1 tagged with spectinomycin in lysogeny region & This study \\
\hline ФAP1.1 $1^{\Delta a c r 23}$ & ФAP1.1-spec with acrllA23 deletion & \\
\hline ФAP1.1 $1^{\text {Aacr23-esc }}$ & ФAP1.1 $1^{\text {sacr23 }}$ escaper of spacer 4 from SF370 & This study \\
\hline ФNM4ү4 & Obligately lytic $S$. aureus pac phage & $\begin{array}{l}\text { (Heler et al., } \\
2015 \text { ) }\end{array}$ \\
\hline pLZ12spec & Spectinomycin resistant cloning vector & $\begin{array}{l}\text { (Husmann et al. } \\
1995 \text { ) }\end{array}$ \\
\hline pC194 & Chloramphenicol-resistant $S$. aureus plasmid & $\begin{array}{l}\text { (Horinouchi and } \\
\text { Weisblum, } \\
\text { 1982a) }\end{array}$ \\
\hline pCasSA & S. aureus genome editing vector & $\begin{array}{l}\text { (Chen et al., } \\
2017 \text { ) }\end{array}$ \\
\hline pCL55 & Integration vector for $S$. aureus & $\begin{array}{l}\text { (Luong and Lee, } \\
\text { 2007) }\end{array}$ \\
\hline pDB114 & Control spacer with cas9 & $\begin{array}{l}\text { (Bikard et al., } \\
\text { 2014) }\end{array}$ \\
\hline pE194 & Erythromycin-resistant $S$. aureus plasmid & $\begin{array}{l}\text { (Horinouchi and } \\
\text { Weisblum, } \\
\text { 1982b) }\end{array}$ \\
\hline pGG-Bsal-R & Type III-A CRISPR-Cas from S. epidermidis on pC194 & $\begin{array}{l}\text { (Goldberg et al., } \\
2014 \text { ) }\end{array}$ \\
\hline pJTR142 & Type III-A CRISPR-Cas from S. epidermidis on pLZ12spec & This study \\
\hline pJTR162 & S. aureus tet inducible expression construct on $\mathrm{pE} 194$ & $\begin{array}{l}\text { (Rostol and } \\
\text { Marraffini, 2019) }\end{array}$ \\
\hline pWJ40 & S. pyogenes type II-A CRISPR-Cas system on pC194 & $\begin{array}{l}\text { (Heler et al., } \\
2015 \text { ) }\end{array}$ \\
\hline pAV121 & Type II-A CRISPR-Cas from S. pyogenes on pCL55 & This study \\
\hline pAV122 & Type II-A CRISPR-Cas from S. pyogenes on pCL55 targeting $\Phi N M 4 \gamma 4$ & This study \\
\hline pAV315 & Type II-A CRISPR-Cas from S. pyogenes targeting ФAP1.1 on pC194 & This study \\
\hline pAV329 & ФAP1.1 editing plasmid to tag with spectinomycin & This study \\
\hline pAV344 & Target site for SF370 spacer 1 on pC194 & This study \\
\hline pAV346 & Target site from ФAP1.1 for SF370 spacer 4 on pC194 & This study \\
\hline pAV354 & Target site from for SF370 spacer 5 on pC194 & This study \\
\hline pAV391 & Control sgRNA expressing vector on $\mathrm{pC} 194$ & This study \\
\hline pAV392 & Perfect ФAP1.1 spacer 4 sgRNA expressing vector on pC194 & This study \\
\hline pAV407 & Target sites from ФAP1.1 for NCTC 13743 spacers on pC194 & This study \\
\hline pAV412 & ФAP1.1 orf4 overexpression plasmid on $\mathrm{pE} 194$ & This study \\
\hline pAV413 & ФAP1.1 acrllA23 overexpression plasmid on $\mathrm{pE} 194$ & This study \\
\hline pAV414 & ФAP1.1 orf1 overexpression plasmid on pJTR162 & This study \\
\hline pAV432 & ФAP1.1 acrllA23 overexpression plasmid on pLZ12spec & This study \\
\hline pAV449 & Type III-A acrllA23 targeting plasmid on pLZ12spec & This study \\
\hline
\end{tabular}




\section{Supplementary table S2. DNA oligonucleotides used in this study.}

\begin{tabular}{|c|c|}
\hline Name & Sequence (5'-3') \\
\hline AV1004 & aaaacCATGTGCTTCTTTCTTTCACACCAAATATA \\
\hline AV1005 & gaacGTTAATACCAAAATCTACATAGACAACCGTTCCATG \\
\hline AV1008 & CAGAAAGAATAGGAAGGTATCCG \\
\hline AV1015 & CGACTGCTGGTATTAACCCTC \\
\hline AV1049 & TTACCGTGCTTTTTTGCCTTC \\
\hline AV1050 & GATTAAAAAAATTATAAATACGCAGAAAATATTTTGGAAAC \\
\hline AV1050 & GATTAAAAAAATTATAAATACGCAGAAAATATTTTGGAAAC \\
\hline AV1051 & GCAAAAAAGCACGGTAAATAACGTAACGTGACTGGCAAGAG \\
\hline AV1052 & TTATAATTTTTTTAATCTGTTATTTAAATAGTTTATAG \\
\hline AV1053 & CAAAACCACATACCTATGTCTTCTTTGTTCATTGGTCTCACC \\
\hline AV1054 & TTATGTGGTTATCGATTGCGGACTTAAAACTATTCCTGAAGC \\
\hline AV1078 & GCGCAAGAAGAAATCAACCAGCGCAATAGGTATGTGGTTTTGTATTGGAAT \\
\hline AV1079 & TTGATTTCTTCTTGCGCTTTTTAGGAATCGATAACCACATAACAGTCATAAAAC \\
\hline AV1089 & GATTACGCCAAGCTTGCACCTTGTCCAAAAGGTCGTGG \\
\hline AV1102 & ACGGTTTACCTGCTAAACAAATTTAATAGGTATGTGGTTTTGTATTGGAAT \\
\hline AV1103 & TTTAGCAGGTAAACCGTGCTTTAGGAATCGATAACCACATAACAGTCATAAAAC \\
\hline AV1113 & GCACACCTAATTTTTCCTCAGCACTATAGGTATGTGGTTTTGTATTGGAAT \\
\hline AV1114 & GGAAAAATTAGGTGTGCTTGGCTGGAATCGATAACCACATAACAGTCATAAAAC \\
\hline AV1127 & CTAAATCAGCAGGTGCTGCTATGG \\
\hline AV1128 & GCAGTACCATTTCCACTGGCTCC \\
\hline AV1149 & CTAAAACAAAAAGCGCAAGAAGAAATC \\
\hline AV1149 & CTAAAACAAAAAGCGCAAGAAGAAATC \\
\hline AV1151 & TCTAAAACAGAGCGCAATTAATTATTGC \\
\hline AV1152 & TAAAACGCCAAGCGCACCTAATTTTT \\
\hline AV1153 & TCTAAAACAAAGCACGGTTTACCTGCTA \\
\hline AV1156 & CTAAGCGACTACCTTATCTCA \\
\hline AV1171 & CGAAATTTTTTAGACAAAAATAGTCTACGAG \\
\hline AV1188 & ATACAAAACCACATACCTATGCGGCCTTTTTACGGTTCCTG \\
\hline AV1189 & CTGTTATGTGGTTATCGATTCAACTTAATCGCCTTGCAGCAC \\
\hline AV1190 & gaaaAAAAATTAGGTGTGCTTGGC \\
\hline AV1191 & aaacGCCAAGCACACCTAATTTTT \\
\hline AV1271 & TTCCTТАССТССТTСТTСАТССТСС \\
\hline AV1272 & AAGAAGGAGGTAAGGAAATGAAATACTTTGTAACAGACATCGAAAAC \\
\hline AV1273 & TATCAATTGTCCAAGAACTAAAATTCAAATCCGTTTTCTTTAGCG \\
\hline AV1274 & AAGAAGGAGGTAAGGAAATGTTTATCTATGTAATAAGGAGAAATAAAATGG \\
\hline AV1275 & TATCAATTGTCCAAGAATTACCCCTTAAAATACCCACAACGTT \\
\hline AV1276 & AAGAAGGAGGTAAGGAAATGAACAAAGAAGACTATCTAAGGTTACTTG \\
\hline AV1277 & TATCAATTGTCCAAGAATTACTTATGCTTGCGAGGCTTGG \\
\hline AV1277 & TATCAATTGTCCAAGAATTACTTATGCTTGCGAGGCTTGG \\
\hline AV1298 & CGCTACTATATCCGCCGTAGTTAC \\
\hline AV1307 & AGTCACGTTACGTTATTCGATCACTCGTTACCATCACGG \\
\hline AV1308 & CTTCAGGTTATGACCATCTCTGAATTCAGTCATAGCTGTACCC \\
\hline AV1339 & CAGTGCCAAGCTGTTAAGGCTTTATATCAATAGATTGGACTACCTG \\
\hline AV1340 & CGTCGACGGTTTCTCTCGGCAGTTATTGGAGAGGCTGAC \\
\hline AV1345 & gaacATATTCCATTTTATTTCTCCTTATTACATAGATAA \\
\hline AV1346 & gatcTTATCTATGTAATAAGGAGAAATAAAATGGAATAT \\
\hline AV186 & AATCGATAACCACATAACAGTCATAAAAC \\
\hline AV204 & ATAGGTATGTGGTTTTGTATTGGAAT \\
\hline AV672 & ATAACGTAACGTGACTGGCAAGA \\
\hline $\mathrm{H} 174$ & TATCGGCACAAATAGCGATGCCACTCTTATCCATCAATCC \\
\hline $\mathrm{H} 175$ & GGATAAGAGTGGCATCGCTATTTGTGCCGATATCTAAGCC \\
\hline $\mathrm{H} 237$ & GGCGTACTGATGAAGATTATTTCTTAATAACTAAAAATATGG \\
\hline $\mathrm{H} 49$ & AAACTGCGCTGGTTGATTTCTTCTTGCGCTTTTTG \\
\hline $\mathrm{H} 53$ & AAACAGGAATATCCGCAATAATTAATTGCGCTCTG \\
\hline $\mathrm{H} 57$ & AAACTAAATTTGTTTAGCAGGTAAACCGTGCTTTG \\
\hline JTR434 & CAGCTATGACCATGATTACGCC \\
\hline JTR438 & GCAGTGAGCGCAACGCAATTAATCCAATCACACCAATAGTTCGAAGAC \\
\hline JTR441 & GGCGTAATCATGGTCATAGCTGCTTCTTGTAGTGAGGGAACGTC \\
\hline JTR598 & TTCTTGGACAATTGATATTATAGGTGCACC \\
\hline
\end{tabular}


bioRxiv preprint doi: https://doi.org/10.1101/2020.10.09.333658; this version posted October 9, 2020. The copyright holder for this preprint (which was not certified by peer review) is the author/funder, who has granted bioRxiv a license to display the preprint in perpetuity. It is made available under aCC-BY-NC-ND 4.0 International license.

\begin{tabular}{ll}
\hline JW293 & ATTAATTGCGTTGCGCTCACTG \\
\hline JW392 & TGTCATGATAATAATGGTTTCTTAGAGTAGGTTTAGCAAGATGGCAGCG \\
\hline JW393 & TTCCCCGAAAATGCCACCTGACGTTGGTATTAACCCTCTTTCTCAAGTTATC \\
\hline JW478 & ACGTCAGGTGGCACTTTTCG \\
\hline JW479 & CTAAGAAACCATTATTATCATGACATTAACC \\
\hline NP114 & TGGTCATAACCTGAAGGAAGATCTG \\
\hline oGG50 & GTTAATGTTACGAATGATGAACC \\
\hline OGG96 & AAGATGCAACAATGGGAACCAAG \\
\hline W1066 & AGTTATTGGTATGACTGGTTTTAAGC \\
\hline W1069 & GCTTAAAACCAGTCATACCAATAAC \\
\hline & $\begin{array}{c}\text { (a)lower case sequences are compatible with the overhangs of Bsal cleavage of the CRISPR } \\
\text { repeat, and are required for spacer cloning. }\end{array}$
\end{tabular}

\section{Supplementary table S3. Plasmid construction in this study.}

\begin{tabular}{|c|c|}
\hline Plasmid & Cloning strategy \\
\hline pJTR142 & $\begin{array}{l}\text { PCR amplification of pGG-Bsal-R with JTR438/JTR441 and pLZ12spec with } \\
\text { JTR434/JW293 followed by a Gibson assembly of the two products }\end{array}$ \\
\hline $\mathrm{pAV} 121$ & $\begin{array}{l}\text { PCR amplification of pWJ40 with JW392/JW393 and pCL55 with JW478/JW479, } \\
\text { followed by a Gibson assembly of the two products }\end{array}$ \\
\hline pAV122 & $\begin{array}{l}\text { PCR amplification of pWJ40 with a } \$ \text { NM4Y4 acquired spacer with JW392/JW393, } \\
\text { and pCL55 pCL55 with JW478/JW479, followed by a Gibson assembly of the two } \\
\text { products }\end{array}$ \\
\hline pAV315 & $\begin{array}{l}\text { Bsal-HF (NEB) digestion of plasmid pDB114, followed by ligation with annealed } \\
\text { oligos AV1004/AV1005 with compatible overhangs }\end{array}$ \\
\hline pAV329 & $\begin{array}{l}\text { PCR amplification pC194 with AV186/AV204, ФAP1.1 with AV1053/AV1050, } \\
\text { pLZ12spec with AV1051/AV1052, ФAP1.1 with AV1049/AV1054 followed by a } \\
\text { Gibson assembly of the four products }\end{array}$ \\
\hline pAV344 & $\begin{array}{l}\text { PCR amplification of pC194 with W1069/AV1078, and with W1066/AV1079, followed } \\
\text { by a Gibson assembly of the two products }\end{array}$ \\
\hline pAV346 & $\begin{array}{l}\text { PCR amplification of pC194 with W1069/AV1102, and with W1066/AV1103, followed } \\
\text { by a Gibson assembly of the two products }\end{array}$ \\
\hline pAV354 & $\begin{array}{l}\text { PCR amplification of pC194 with W1069/AV1113, and with W1066/AV1114, followed } \\
\text { by a Gibson assembly of the two products }\end{array}$ \\
\hline pAV391 & $\begin{array}{l}\text { PCR amplification of pC194 with AV186/AV204, pCas-SA with AV1189/H174 and } \\
\text { pCas-SA with AV1188/H175, followed by a Gibson assembly of the three products }\end{array}$ \\
\hline pAV392 & $\begin{array}{l}\text { Bsal-HF (NEB) digestion of plasmid pAV391, followed by ligation with } \\
\text { annealed oligos AV1190 and AV1191 with compatible overhangs }\end{array}$ \\
\hline pAV407 & $\begin{array}{l}\text { PCR amplification pC194 with AV186/AV204, followed by a Gibson assembly with } \\
\text { NCTC13743 targets synthesized dsDNA }\end{array}$ \\
\hline pAV412 & $\begin{array}{l}\text { PCR amplification of pJTR162 with JTR598/AV1271, and ФAP1.1 with } \\
\text { AV1272/AV1273, followed by a Gibson assembly of the two products }\end{array}$ \\
\hline pAV413 & $\begin{array}{l}\text { PCR amplification of pJTR162 with JTR598/AV1271, and ФAP1.1 with } \\
\text { AV1274/AV1275, followed by a Gibson assembly of the two products }\end{array}$ \\
\hline pAV414 & $\begin{array}{l}\text { PCR amplification of pJTR162 with JTR598/AV1271, and ФAP1.1 with } \\
\text { AV1276/AV1277, followed by a Gibson assembly of the two products }\end{array}$ \\
\hline pAV432 & $\begin{array}{l}\text { PCR amplification of pLZ12 spec with NP114/AV672, and pAV413 with } \\
\text { AV1307/AV1308, followed by a Gibson assembly of the two products }\end{array}$ \\
\hline pAV449 & $\begin{array}{l}\text { Bsal-HF (NEB) digestion of plasmid pJTR142, followed by ligation with } \\
\text { annealed oligos AV1345 and AV1346 with compatible overhangs }\end{array}$ \\
\hline
\end{tabular}

\section{Synthetic DNA in this study}

$>$ NCTC13743_targets

ATACAAAACCACATACCTATAACATGTACGAGCTCAACAGTATTTTAGCAGATGTGTATGTCAAATTGATTGGTGGAGAGCCAGATGACCGGAACTA TTGAGAGTCACAACATCAGGACTGGTCAATTAACTGTTGAGGAGTGGCAACGGCTTATCTATGATATGGGAGCAGGAACACCTTTAGGCAGTATGTT TATCGAATTGGGTCTTGATACATCAAAATTTGATCCAATCGATAACCACATAACAG 


\section{References}

(2016). In Streptococcus pyogenes : Basic Biology to Clinical Manifestations, J.J. Ferretti, D.L. Stevens, and V.A. Fischetti, eds. (Oklahoma City (OK)).

Bankevich, A., Nurk, S., Antipov, D., Gurevich, A.A., Dvorkin, M., Kulikov, A.S., Lesin, V.M., Nikolenko, S.I., Pham, S., Prjibelski, A.D., et al. (2012). SPAdes: a new genome assembly algorithm and its applications to single-cell sequencing. J Comput Biol 19, 455-477.

Banks, D.J., Beres, S.B., and Musser, J.M. (2002). The fundamental contribution of phages to GAS evolution, genome diversification and strain emergence. Trends Microbiol 10, 515-521.

Barrangou, R., Fremaux, C., Deveau, H., Richards, M., Boyaval, P., Moineau, S., Romero, D.A., and Horvath, P. (2007). CRISPR provides acquired resistance against viruses in prokaryotes. Science $315,1709-1712$.

Bikard, D., Euler, C.W., Jiang, W., Nussenzweig, P.M., Goldberg, G.W., Duportet, X., Fischetti, V.A., and Marraffini, L.A. (2014). Exploiting CRISPR-Cas nucleases to produce sequence-specific antimicrobials. Nat Biotechnol 32, 1146-1150.

Bondy-Denomy, J., Davidson, A.R., Doudna, J.A., Fineran, P.C., Maxwell, K.L., Moineau, S., Peng, X., Sontheimer, E.J., and Wiedenheft, B. (2018). A Unified Resource for Tracking Anti-CRISPR Names. CRISPR J 1, 304-305.

Bondy-Denomy, J., Pawluk, A., Maxwell, K.L., and Davidson, A.R. (2013).

Bacteriophage genes that inactivate the CRISPR/Cas bacterial immune system. Nature 493, 429-432.

Borges, A.L., Zhang, J.Y., Rollins, M.F., Osuna, B.A., Wiedenheft, B., and BondyDenomy, J. (2018). Bacteriophage Cooperation Suppresses CRISPR-Cas3 and Cas9 Immunity. Cell 174, 917-925 e910.

Brouns, S.J., Jore, M.M., Lundgren, M., Westra, E.R., Slijkhuis, R.J., Snijders, A.P., Dickman, M.J., Makarova, K.S., Koonin, E.V., and van der Oost, J. (2008). Small CRISPR RNAs guide antiviral defense in prokaryotes. Science 321, 960-964.

Chen, W., Zhang, Y., Yeo, W.S., Bae, T., and Ji, Q. (2017). Rapid and Efficient Genome Editing in Staphylococcus aureus by Using an Engineered CRISPR/Cas9 System. J Am Chem Soc 139, 3790-3795.

Coleman, D., Knights, J., Russell, R., Shanley, D., Birkbeck, T.H., Dougan, G., and Charles, I. (1991). Insertional inactivation of the Staphylococcus aureus beta-toxin by bacteriophage phi 13 occurs by site- and orientation-specific integration of the phi 13 genome. Mol Microbiol 5, 933-939.

Cong, L., Ran, F.A., Cox, D., Lin, S., Barretto, R., Habib, N., Hsu, P.D., Wu, X., Jiang, W., Marraffini, L.A., et al. (2013). Multiplex Genome Engineering Using CRISPR/Cas Systems. Science 339, 819-823.

Davidson, A.R., Lu, W.T., Stanley, S.Y., Wang, J., Mejdani, M., Trost, C.N., Hicks, B.T., Lee, J., and Sontheimer, E.J. (2020). Anti-CRISPRs: Protein Inhibitors of CRISPR-Cas Systems. Annu Rev Biochem 89, 309-332. 
Deltcheva, E., Chylinski, K., Sharma, C.M., Gonzales, K., Chao, Y., Pirzada, Z.A., Eckert, M.R., Vogel, J., and Charpentier, E. (2011). CRISPR RNA maturation by transencoded small RNA and host factor RNase III. Nature 471, 602-607.

Desiere, F., McShan, W.M., van Sinderen, D., Ferretti, J.J., and Brussow, H. (2001). Comparative genomics reveals close genetic relationships between phages from dairy bacteria and pathogenic Streptococci: evolutionary implications for prophage-host interactions. Virology 288, 325-341.

Deveau, H., Barrangou, R., Garneau, J.E., Labonte, J., Fremaux, C., Boyaval, P., Romero, D.A., Horvath, P., and Moineau, S. (2008). Phage response to CRISPRencoded resistance in Streptococcus thermophilus. J Bacteriol 190, 1390-1400.

Eitzinger, S., Asif, A., Watters, K.E., lavarone, A.T., Knott, G.J., Doudna, J.A., and Minhas, F. (2020). Machine learning predicts new anti-CRISPR proteins. Nucleic Acids Res 48, 4698-4708.

Euler, C.W., Juncosa, B., Ryan, P.A., Deutsch, D.R., McShan, W.M., and Fischetti, V.A. (2016). Targeted Curing of All Lysogenic Bacteriophage from Streptococcus pyogenes Using a Novel Counter-selection Technique. PLoS One 11, e0146408.

Ferretti, J.J., McShan, W.M., Ajdic, D., Savic, D.J., Savic, G., Lyon, K., Primeaux, C., Sezate, S., Suvorov, A.N., Kenton, S., et al. (2001). Complete genome sequence of an M1 strain of Streptococcus pyogenes. Proc Natl Acad Sci USA 98, 4658-4663.

Fiebig, A., Loof, T.G., Babbar, A., Itzek, A., Koehorst, J.J., Schaap, P.J., and NitscheSchmitz, D.P. (2015). Comparative genomics of Streptococcus pyogenes M1 isolates differing in virulence and propensity to cause systemic infection in mice. Int J Med Microbiol 305, 532-543.

Fischetti, V.A. (2007). In vivo acquisition of prophage in Streptococcus pyogenes. Trends Microbiol 15, 297-300.

Forsberg, K.J., Bhatt, I.V., Schmidtke, D.T., Javanmardi, K., Dillard, K.E., Stoddard, B.L., Finkelstein, I.J., Kaiser, B.K., and Malik, H.S. (2019). Functional metagenomicsguided discovery of potent Cas9 inhibitors in the human microbiome. Elife 8.

Garneau, J.E., Dupuis, M.E., Villion, M., Romero, D.A., Barrangou, R., Boyaval, P., Fremaux, C., Horvath, P., Magadan, A.H., and Moineau, S. (2010). The CRISPR/Cas bacterial immune system cleaves bacteriophage and plasmid DNA. Nature 468, 67-71.

Garneau, J.R., Depardieu, F., Fortier, L.C., Bikard, D., and Monot, M. (2017).

PhageTerm: a tool for fast and accurate determination of phage termini and packaging mechanism using next-generation sequencing data. Sci Rep 7, 8292.

Gasiunas, G., Barrangou, R., Horvath, P., and Siksnys, V. (2012). Cas9-crRNA ribonucleoprotein complex mediates specific DNA cleavage for adaptive immunity in bacteria. Proc Natl Acad Sci USA 109, E2579-2586.

Goldberg, G.W., Jiang, W., Bikard, D., and Marraffini, L.A. (2014). Conditional tolerance of temperate phages via transcription-dependent CRISPR-Cas targeting. Nature 514, 633-637. 
Heler, R., Samai, P., Modell, J.W., Weiner, C., Goldberg, G.W., Bikard, D., and Marraffini, L.A. (2015). Cas9 specifies functional viral targets during CRISPR-Cas adaptation. Nature 519, 199-202.

Horinouchi, S., and Weisblum, B. (1982a). Nucleotide sequence and functional map of pC194, a plasmid that specifies inducible chloramphenicol resistance. J Bacteriol 150, 815-825.

Horinouchi, S., and Weisblum, B. (1982b). Nucleotide sequence and functional map of pE194, a plasmid that specifies inducible resistance to macrolide, lincosamide, and streptogramin type B antibodies. J Bacteriol 150, 804-814.

Howard-Varona, C., Hargreaves, K.R., Abedon, S.T., and Sullivan, M.B. (2017). Lysogeny in nature: mechanisms, impact and ecology of temperate phages. ISME J 11, 1511-1520.

Husmann, L.K., Scott, J.R., Lindahl, G., and Stenberg, L. (1995). Expression of the Arp protein, a member of the M protein family, is not sufficient to inhibit phagocytosis of Streptococcus pyogenes. Infect Immun 63, 345-348.

Hynes, A.P., Rousseau, G.M., Lemay, M.L., Horvath, P., Romero, D.A., Fremaux, C., and Moineau, S. (2017). An anti-CRISPR from a virulent streptococcal phage inhibits Streptococcus pyogenes Cas9. Nat Microbiol 2, 1374-1380.

Jansen, R., Embden, J.D., Gaastra, W., and Schouls, L.M. (2002). Identification of genes that are associated with DNA repeats in prokaryotes. Mol Microbiol 43, 15651575.

Jinek, M., Chylinski, K., Fonfara, I., Hauer, M., Doudna, J.A., and Charpentier, E. (2012). A programmable dual-RNA-guided DNA endonuclease in adaptive bacterial immunity. Science 337, 816-821.

Kjems, E. (1958). Studies on streptococcal bacteriophages. 2. Adsorption, lysogenization, and one-step growth experiments. Acta Pathol Microbiol Scand 42, 5666.

Kreiswirth, B.N., Lofdahl, S., Betley, M.J., O'Reilly, M., Schlievert, P.M., Bergdoll, M.S., and Novick, R.P. (1983). The toxic shock syndrome exotoxin structural gene is not detectably transmitted by a prophage. Nature 305, 709-712.

Landsberger, M., Gandon, S., Meaden, S., Rollie, C., Chevallereau, A., Chabas, H., Buckling, A., Westra, E.R., and van Houte, S. (2018). Anti-CRISPR Phages Cooperate to Overcome CRISPR-Cas Immunity. Cell 174, 908-916 e912.

Langmead, B., and Salzberg, S.L. (2012). Fast gapped-read alignment with Bowtie 2. Nat Methods 9, 357-359.

Lee, C.Y., Buranen, S.L., and Ye, Z.H. (1991). Construction of single-copy integration vectors for Staphylococcus aureus. Gene 103, 101-105.

Lee, C.Y., and landolo, J.J. (1986). Lysogenic conversion of staphylococcal lipase is caused by insertion of the bacteriophage L54a genome into the lipase structural gene. J Bacteriol 166, 385-391. 
Luong, T.T., and Lee, C.Y. (2007). Improved single-copy integration vectors for Staphylococcus aureus. J Microbiol Methods 70, 186-190.

Mahendra, C., Christie, K.A., Osuna, B.A., Pinilla-Redondo, R., Kleinstiver, B.P., and Bondy-Denomy, J. (2020). Broad-spectrum anti-CRISPR proteins facilitate horizontal gene transfer. Nat Microbiol 5, 620-629.

Makarova, K.S., Wolf, Y.I., Iranzo, J., Shmakov, S.A., Alkhnbashi, O.S., Brouns, S.J.J., Charpentier, E., Cheng, D., Haft, D.H., Horvath, P., et al. (2020). Evolutionary classification of CRISPR-Cas systems: a burst of class 2 and derived variants. Nat Rev Microbiol 18, 67-83.

Mali, P., Yang, L., Esvelt, K.M., Aach, J., Guell, M., Dicarlo, J.E., Norville, J.E., and Church, G.M. (2013). RNA-Guided Human Genome Engineering via Cas9. Science 339, 823-826.

Marino, N.D., Zhang, J.Y., Borges, A.L., Sousa, A.A., Leon, L.M., Rauch, B.J., Walton, R.T., Berry, J.D., Joung, J.K., Kleinstiver, B.P., et al. (2018). Discovery of widespread type I and type V CRISPR-Cas inhibitors. Science 362, 240-242.

Marraffini, L.A., and Sontheimer, E.J. (2008). CRISPR interference limits horizontal gene transfer in staphylococci by targeting DNA. Science 322, 1843-1845.

McCullor, K., Postoak, B., Rahman, M., King, C., and McShan, W.M. (2018). Genomic Sequencing of High-Efficiency Transducing Streptococcal Bacteriophage A25:

Consequences of Escape from Lysogeny. J Bacteriol 200.

McGinn, J., and Marraffini, L.A. (2016). CRISPR-Cas systems optimize their immune response by specifying the site of spacer integration. Mol Cell 64, 616-623.

Modell, J.W., Jiang, W., and Marraffini, L.A. (2017). CRISPR-Cas systems exploit viral DNA injection to establish and maintain adaptive immunity. Nature 544, 101-104.

Nelson, D., Schuch, R., Chahales, P., Zhu, S., and Fischetti, V.A. (2006). PlyC: a multimeric bacteriophage lysin. Proc Natl Acad Sci U S A 103, 10765-10770.

Nozawa, T., Furukawa, N., Aikawa, C., Watanabe, T., Haobam, B., Kurokawa, K., Maruyama, F., and Nakagawa, I. (2011). CRISPR inhibition of prophage acquisition in Streptococcus pyogenes. PLoS One 6, e19543.

Nussenzweig, P.M., McGinn, J., and Marraffini, L.A. (2019). Cas9 Cleavage of Viral Genomes Primes the Acquisition of New Immunological Memories. Cell Host Microbe 26, 515-526 e516.

Osuna, B.A., Karambelkar, S., Mahendra, C., Sarbach, A., Johnson, M.C., Kilcher, S., and Bondy-Denomy, J. (2020). Critical Anti-CRISPR Locus Repression by a Bifunctional Cas9 Inhibitor. Cell Host Microbe.

Pall, G.S., and Hamilton, A.J. (2008). Improved northern blot method for enhanced detection of small RNA. Nat Protoc 3, 1077-1084.

Pawluk, A., Staals, R.H., Taylor, C., Watson, B.N., Saha, S., Fineran, P.C., Maxwell, K.L., and Davidson, A.R. (2016). Inactivation of CRISPR-Cas systems by anti-CRISPR proteins in diverse bacterial species. Nat Microbiol 1, 16085. 
Perez-Casal, J., Caparon, M.G., and Scott, J.R. (1991). Mry, a trans-acting positive regulator of the M protein gene of Streptococcus pyogenes with similarity to the receptor proteins of two-component regulatory systems. J Bacteriol 173, 2617-2624.

Rauch, B.J., Silvis, M.R., Hultquist, J.F., Waters, C.S., McGregor, M.J., Krogan, N.J., and Bondy-Denomy, J. (2017). Inhibition of CRISPR-Cas9 with Bacteriophage Proteins. Cell 168, 150-158 e110.

Rostol, J.T., and Marraffini, L.A. (2019). Non-specific degradation of transcripts promotes plasmid clearance during type III-A CRISPR-Cas immunity. Nat Microbiol 4, 656-662.

Stanley, S.Y., Borges, A.L., Chen, K.H., Swaney, D.L., Krogan, N.J., Bondy-Denomy, J., and Davidson, A.R. (2019). Anti-CRISPR-Associated Proteins Are Crucial Repressors of Anti-CRISPR Transcription. Cell 178, 1452-1464 e1413.

Taylor, A.L. (1963). Bacteriophage-Induced Mutation in Escherichia Coli. Proc Natl Acad Sci U S A 50, 1043-1051.

Uribe, R.V., van der Helm, E., Misiakou, M.A., Lee, S.W., Kol, S., and Sommer, M.O.A. (2019). Discovery and Characterization of Cas9 Inhibitors Disseminated across Seven Bacterial Phyla. Cell Host Microbe 25, 233-241 e235.

Varble, A., Meaden, S., Barrangou, R., Westra, E.R., and Marraffini, L.A. (2019). Recombination between phages and CRISPR-cas loci facilitates horizontal gene transfer in staphylococci. Nat Microbiol 4, 956-963.

Watson, B.N.J., Staals, R.H.J., and Fineran, P.C. (2018). CRISPR-Cas-Mediated Phage Resistance Enhances Horizontal Gene Transfer by Transduction. MBio 9.

Wright, A.V., and Doudna, J.A. (2016). Protecting genome integrity during CRISPR immune adaptation. Nat Struct Mol Biol 23, 876-883.

Xiao, Y., Ng, S., Nam, K.H., and Ke, A. (2017). How type II CRISPR-Cas establish immunity through Cas1-Cas2-mediated spacer integration. Nature 550, 137-141.

Yamada, S., Shibasaki, M., Murase, K., Watanabe, T., Aikawa, C., Nozawa, T., and Nakagawa, I. (2019). Phylogenetic relationship of prophages is affected by CRISPR selection in Group A Streptococcus. BMC Microbiol 19, 24.

Yin, Y., Yang, B., and Entwistle, S. (2019). Bioinformatics Identification of Anti-CRISPR Loci by Using Homology, Guilt-by-Association, and CRISPR Self-Targeting Spacer Approaches. mSystems 4. 
bioRxiv preprint doi: https://doi org/101101/2020.10.09 333658; this version posted October 9, 2020. The copyright holder for this preprint (which was not certified by peer review) is the author/funder, who has granted bioRxiv a license to display the preprint in perpetuity. It is made available under aCC-BY-NC-ND 4.0 International license.

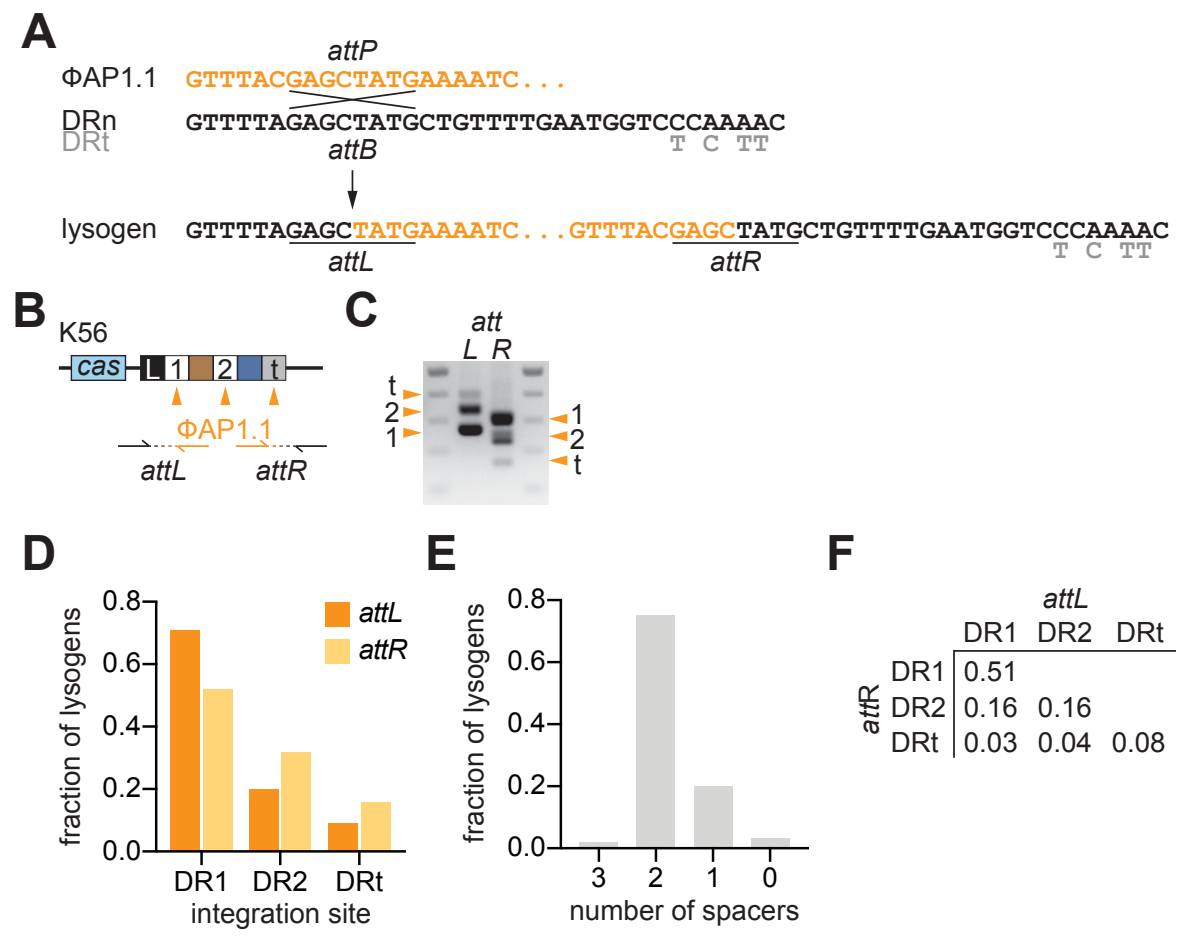

\section{Varble et al., Fig. 1}


A

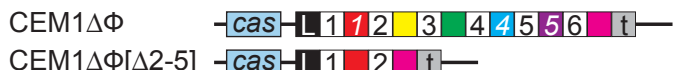

C

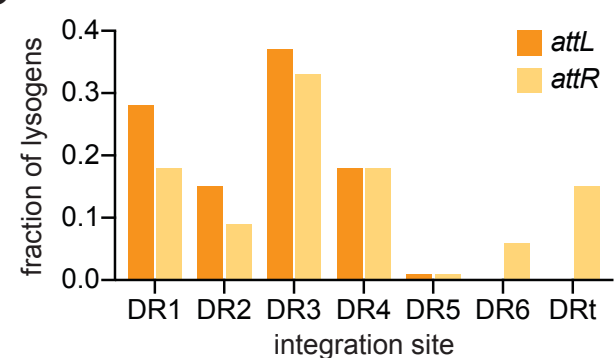

D

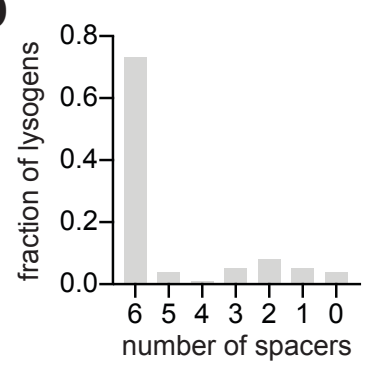

$\mathbf{F}$

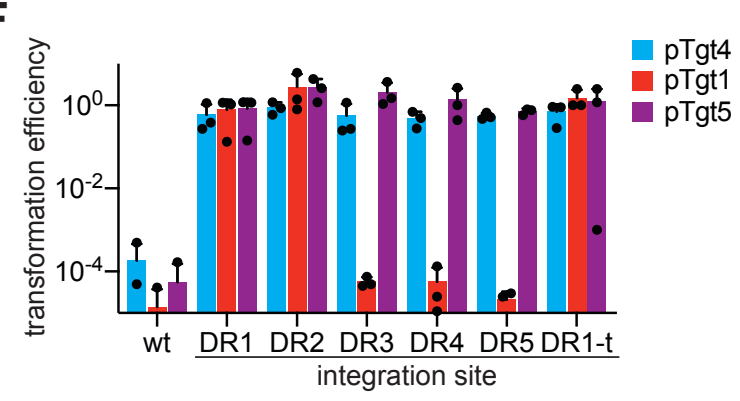

E
B

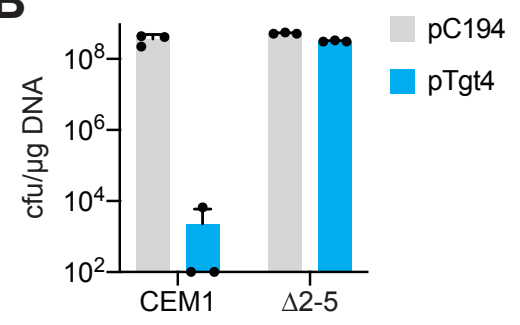

attL

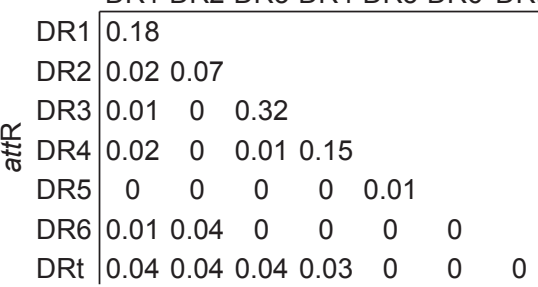

G

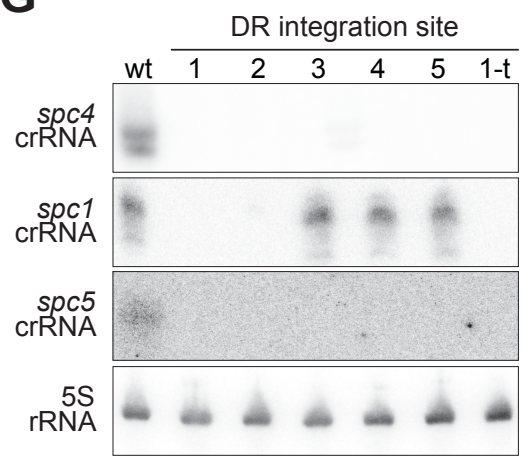

\section{Varble et al., Fig. 2}


A

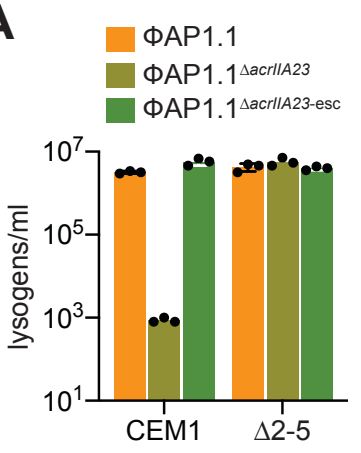

B

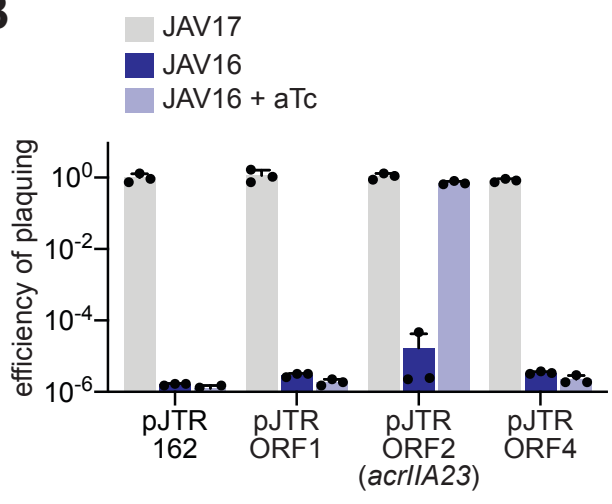

Varble et al., Fig. 3

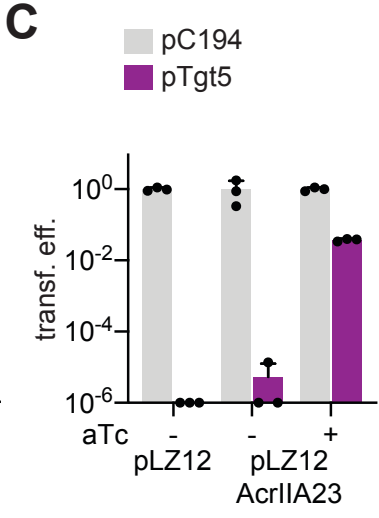




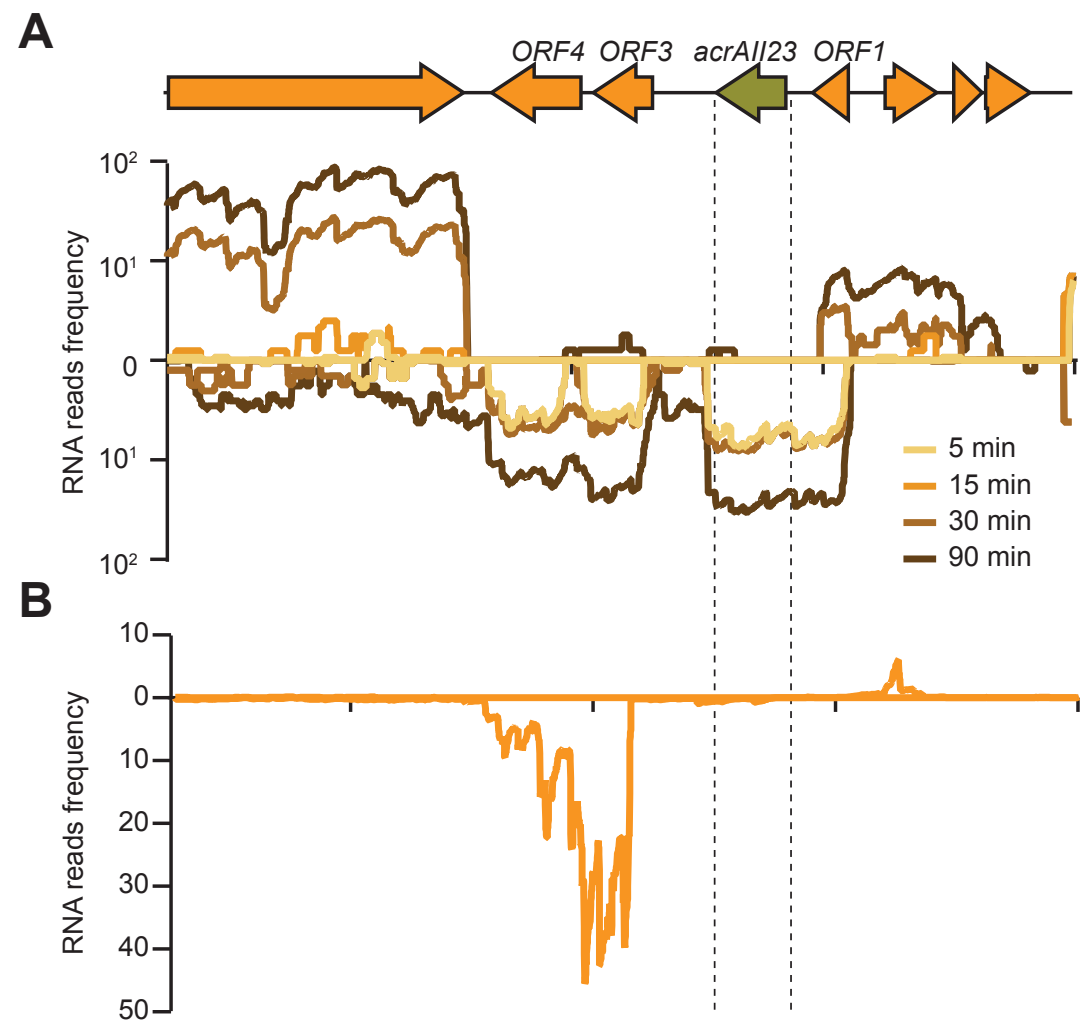

\section{Varble et al., Fig. 4}


A

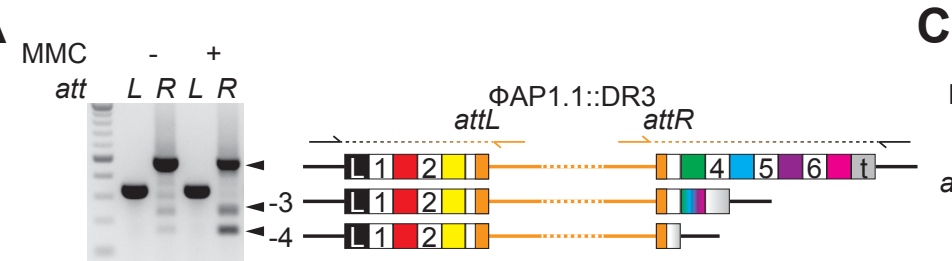

C

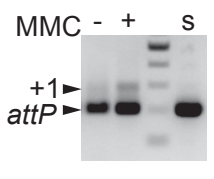

B

$\mathrm{MMC}-$
att $-L R L R$

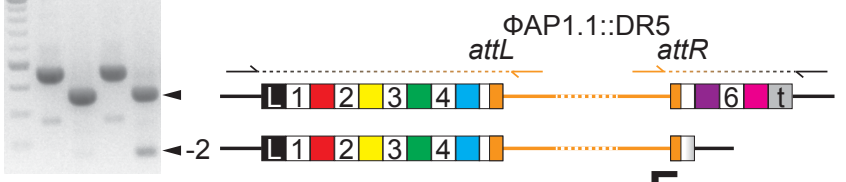

D

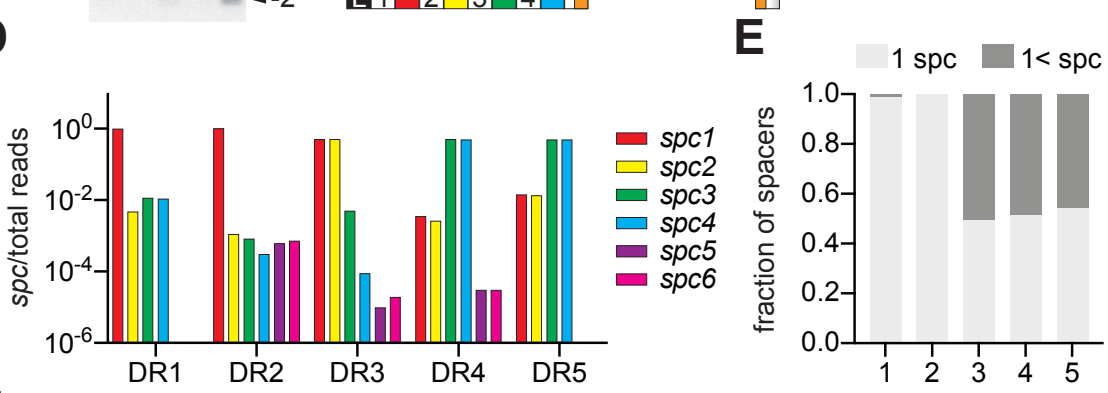

$\mathbf{F}$

K56 $\quad \Rightarrow \mathrm{L} 112 \square \mathrm{t}-$

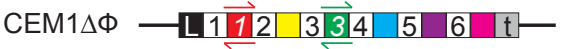

CEM1(ФAP1.1)

DR integration

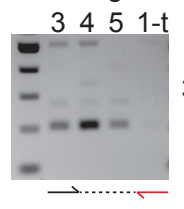

$10 / 14-$ L

$3 / 14-\mathrm{L} / \mathrm{H}_{\text {I }}$

$1 / 14$ - L ||$_{|l|}$

9/14 - L

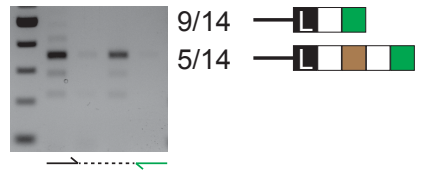

CEM1(ФAP1.1)

DR integration
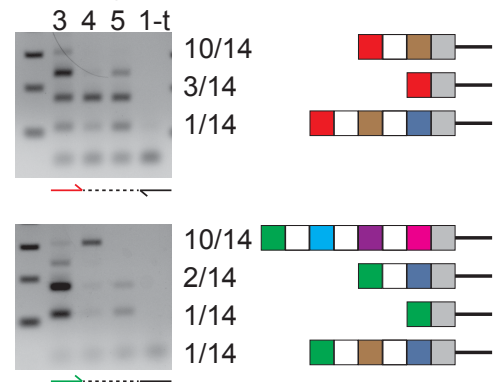

\section{Varble et al., Fig. 5}


bioRxiv preprint doi: https:/doi org/10.1101/202010.09 333658. this version posted October 9 2020. The copyright holder for this preprint (which was not certified by peer review) is the author/funder, who has granted bioRxiv a license to display the preprint in perpetuity. It is made available under aCC-BY-NC-ND 4.0 International license.

A

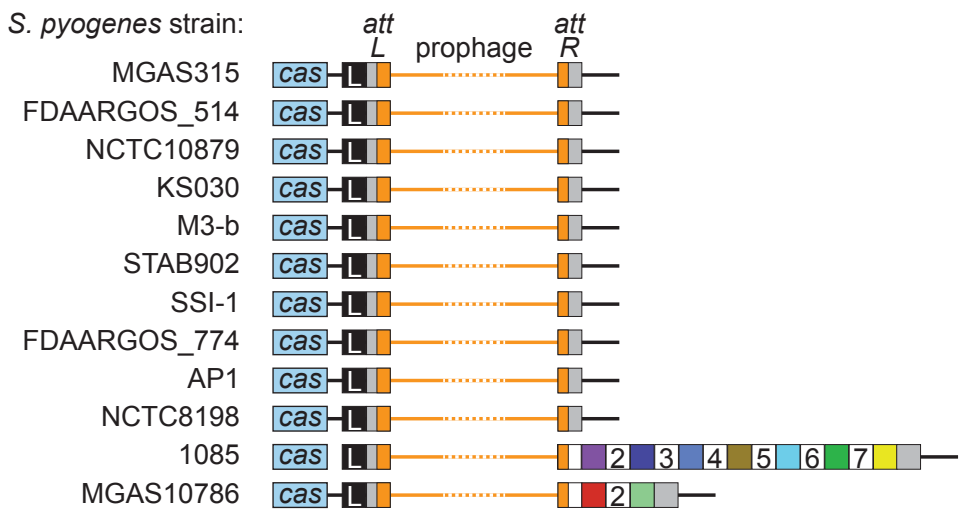

B

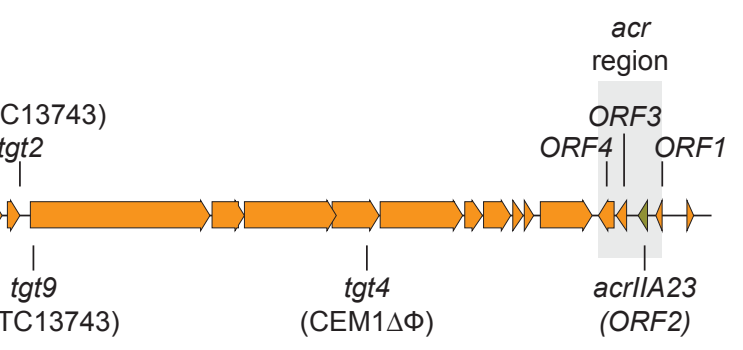

$\operatorname{aad} A$

(NCTC13743)

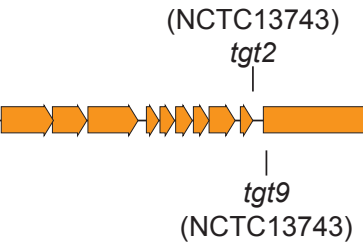

C

K56 -cas-L1 12 t

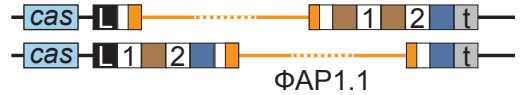

D

crRNA-spc4 UUUUUAAUCCACACGAACCG ФAP1.1-tgt4 ÄÄÄTTAGGTGCGCTTGGCACC

crRNA-spc4 UUUUUAAUCCACACGAACCG

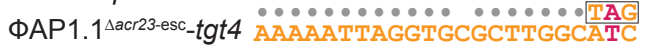

\section{Varble et al., Fig. S1}


bioRxiv preprint doi: https://doi. org/10.1101/2020.10.09 333658; this version posted October 9,2020 . The copyright holder for this preprint (which was not certified by peer review) is the author/funder, who has granted bioRxiv a license to display the preprint in perpetuity. It is made available under aCC-BY-NC-ND 4.0 International license.

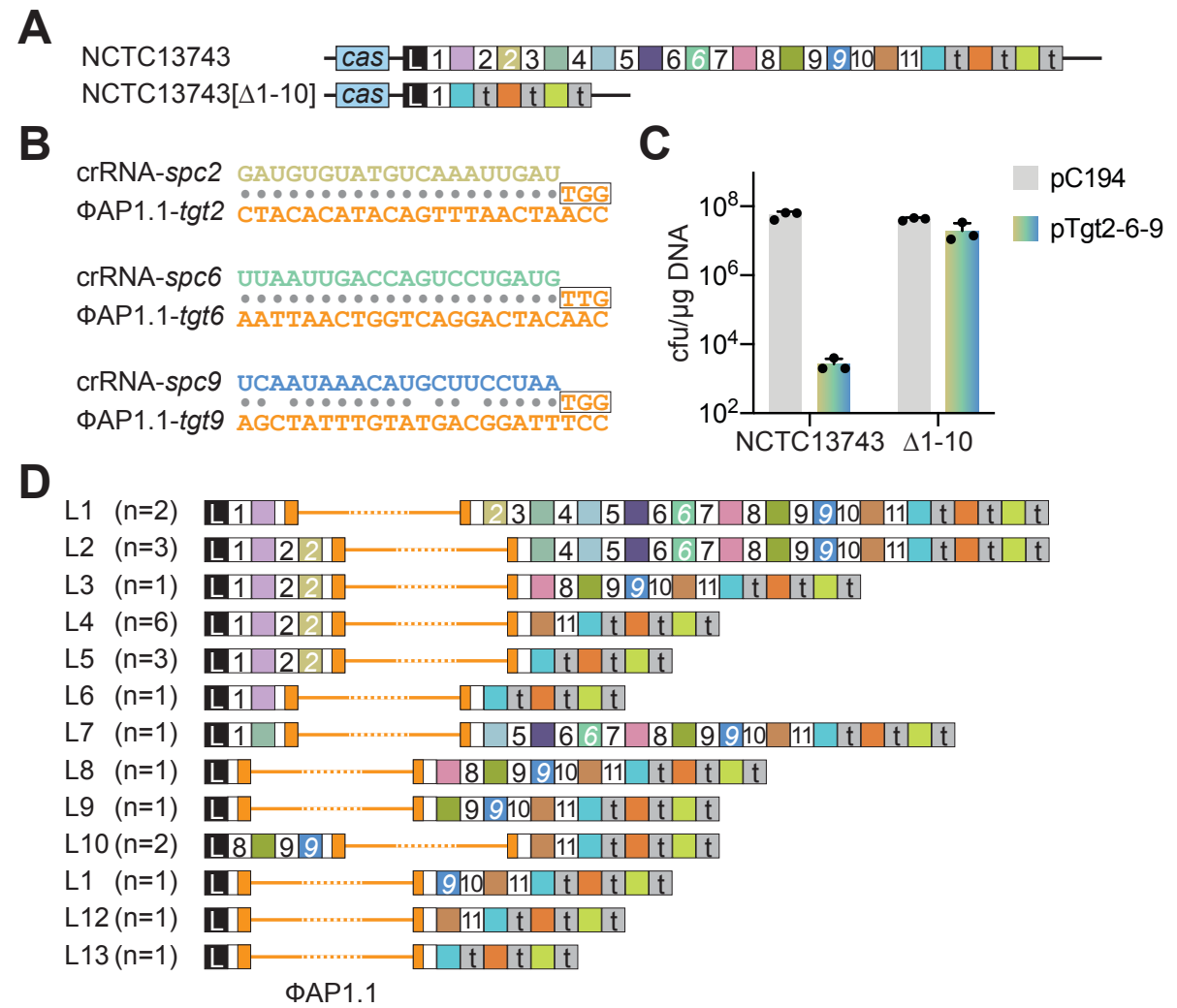

\section{Varble et al., Fig. S2}


bioRxiv preprint doi: https://doi.org/10.1101/2020.10.09.333658; this version posted October 9, 2020. The copyright holder for this preprint (which was not certified by peer review) is the author/funder, who has granted bioRxiv a license to display the preprint in perpetuity. It is made available under aCC-BY-NC-ND 4.0 International license.

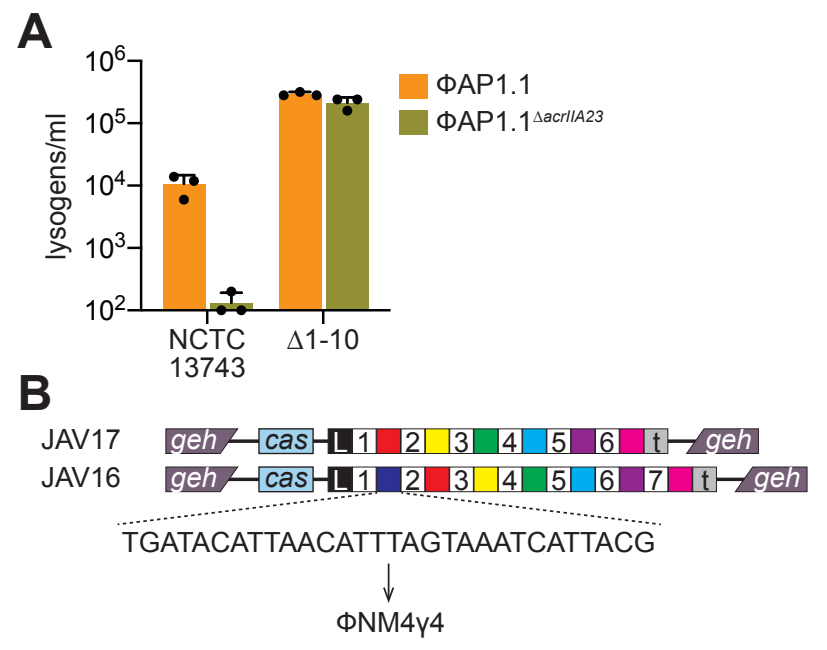

\section{Varble et al., Fig. S3}


A

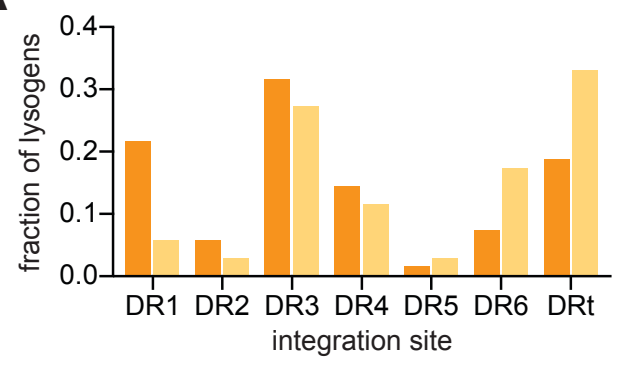

B

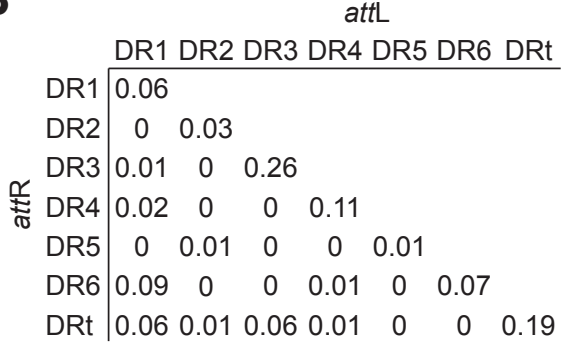

C

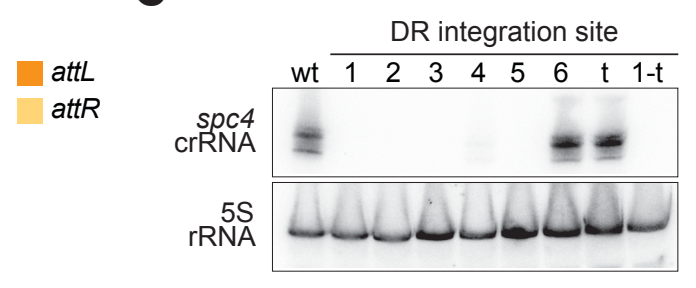

D

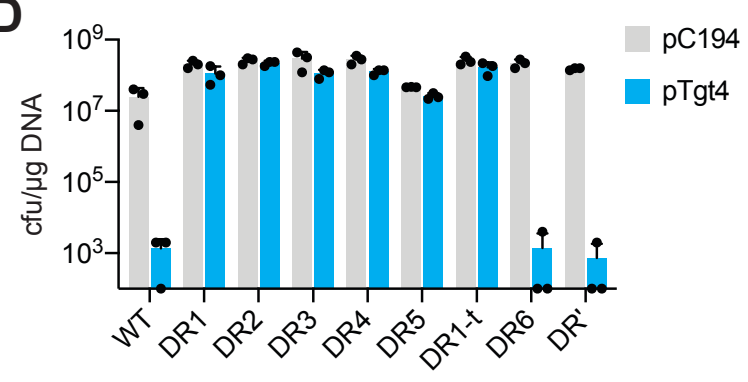

\section{Varble et al., Fig. S4}


A

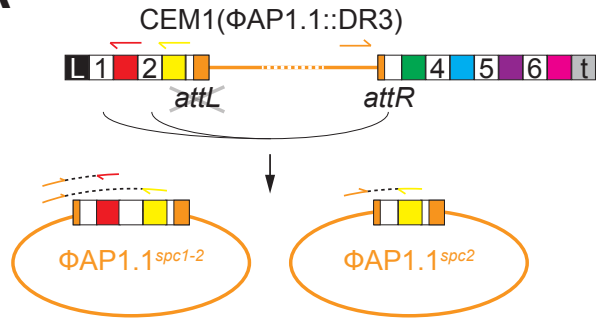

B
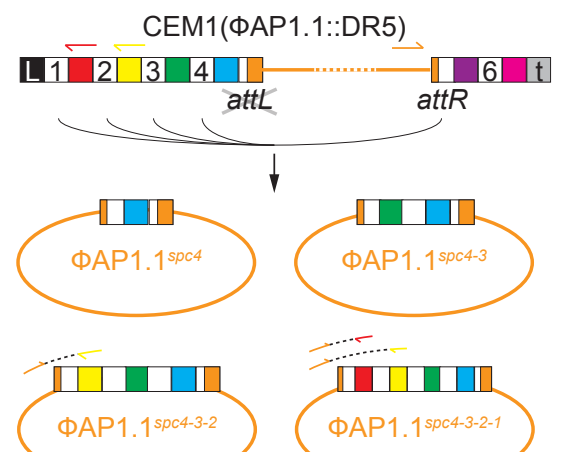

C

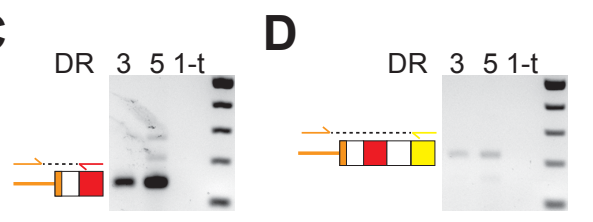

E
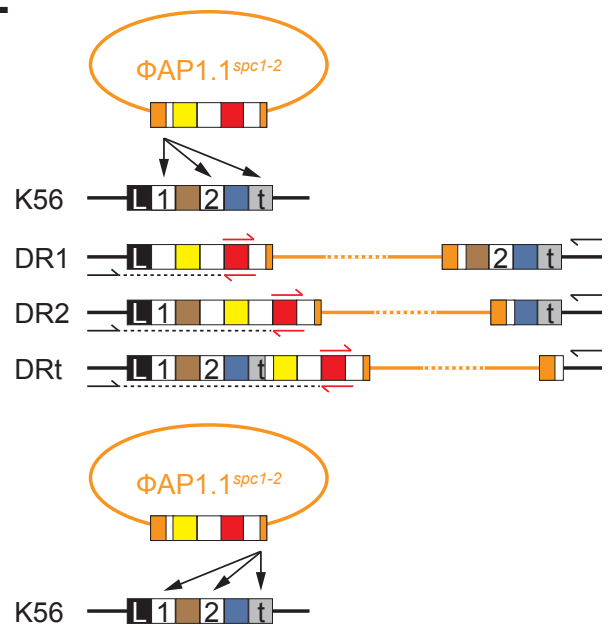

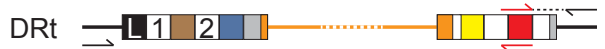

DR2 تL1 $1 \square-\cdots \cdots$

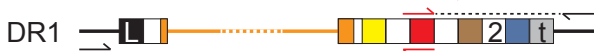

\section{Varble et al., Fig. S5}

